\title{
Higher Temperature Reactor Materials Workshop Sponsored by the Department of Energy Office of Nuclear Energy, Science, and Technology (NE) and the Office of Basic Energy Sciences (BES) March 18-21, 2002 La Jolla, CA
}

Todd Allen, Argonne National Laboratory-West Steve Bruemmer, Pacific Northwest National Laboratory Mike Kassner, Oregon State University Robert Odette, University of California, Santa Barbara

Roger Stoller, Oak Ridge National Laboratory Gary Was, University of Michigan

Wilhelm Wolfer, Lawrence Livermore National Laboratory

Steve Zinkle, Oak Ridge National Laboratory John Elmer, Lawrence Livermore National Laboratory Arthur Motta, Pennsylvania State University

June 2002
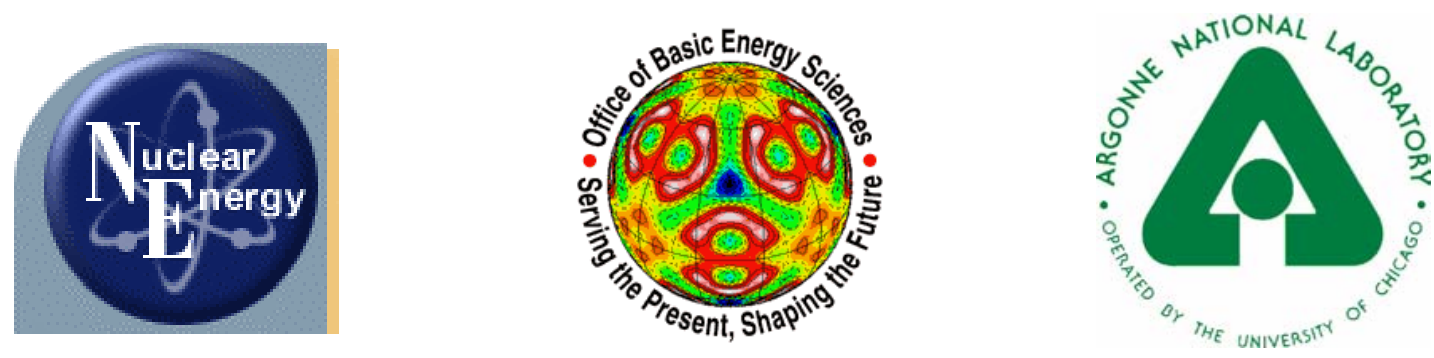
Argonne National Laboratory, with facilities in the states of Illinois and Idaho, is owned by the United States Government and operated by The University of Chicago under the provisions of a contract with the Department of Energy.

\section{DISCLAIMER}

This report was prepared as an account of work sponsored by an agency of the United States Government. Neither the United States Government nor any agency thereof, nor The University of Chicago, nor any of their employees or officers, makes any warranty, express or implied, or assumes any legal liability or responsibility for the accuracy, completeness, or usefulness of any information, apparatus, product, or process disclosed, or represents that its use would not infringe privately owned rights. Reference herein to any specific commercial product, process, or service by trade name, trademark, manufacturer, or otherwise does not necessarily constitute or imply its endorsement, recommendation, or favoring by the United States Government or any agency thereof. The views and opinions of document authors expressed herein do not necessarily state or reflect those of the United States Government or any agency thereof, Argonne National Laboratory, or The University of Chicago.

Available electronically at http://www.doe.gov/bridge

Available for a processing fee to U.S. Department of Energy and its contractors, in paper, from:

U.S. Department of Energy

Office of Scientific and Technical Information

P.O. Box 62

Oak Ridge, TN 37831-0062

phone: (865) 576-8401

fax: (865) 576-5728

email: reports@adonis.osti.gov 


\title{
Higher Temperature Reactor Materials Workshop \\ Sponsored by the Department of Energy Office of Nuclear Energy, Science, and Technology (NE) and the Office of Basic Energy Sciences (BES) \\ March 18-21, 2002 \\ La Jolla, CA
}

\author{
Authors \\ Todd Allen, Argonne National Laboratory-West \\ Steve Bruemmer, Pacific Northwest National Laboratory \\ Mike Kassner, Oregon State University \\ Robert Odette, University of California, Santa Barbara \\ Roger Stoller, Oak Ridge National Laboratory \\ Gary Was, University of Michigan \\ Wilhelm Wolfer, Lawrence Livermore National Laboratory \\ Steve Zinkle, Oak Ridge National Laboratory \\ John Elmer, Lawrence Livermore National Laboratory \\ Arthur Motta, The Pennsylvania State University
}

\begin{abstract}
Inspiration
"We physicists can dream up and work out all the details of power reactors based on dozens of combinations of the essentials, but it is only a paper reactor until the metallurgist tells us whether it can be built and from what. Then only can one figure whether there is any hope that they can provide power."
\end{abstract}

Dr. Norman Hilberry, former Director, Argonne National Laboratory 


\section{Table of Contents}

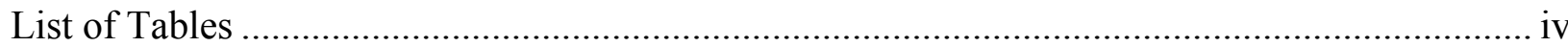

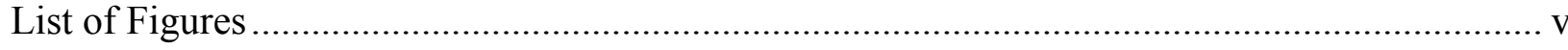

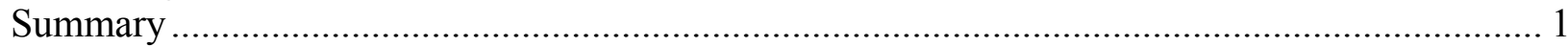

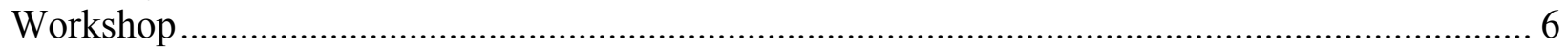

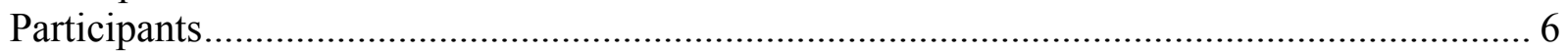

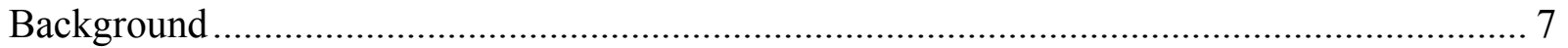

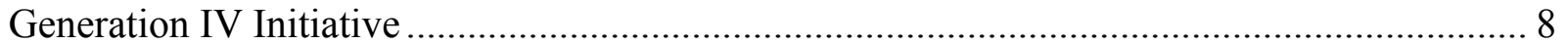

Design Needs-Mission Performance, Safety, Operability .................................................. 9

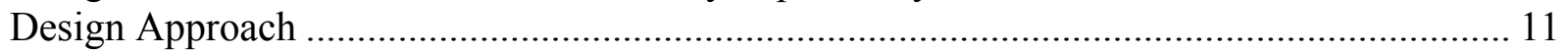

Interaction between Radiation Damage and Microstructure ............................................ 12

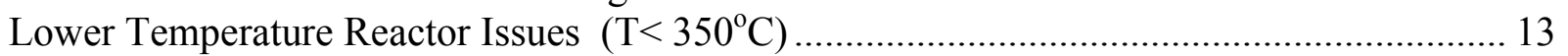

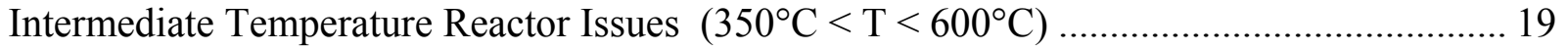

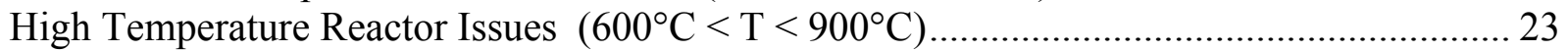

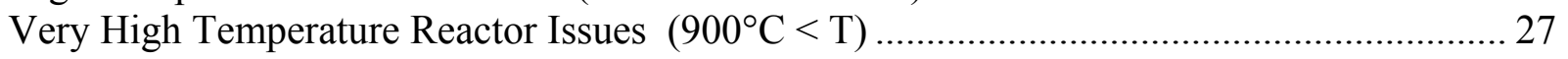

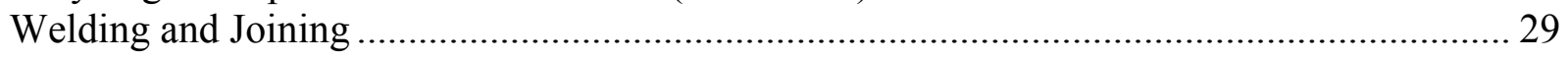

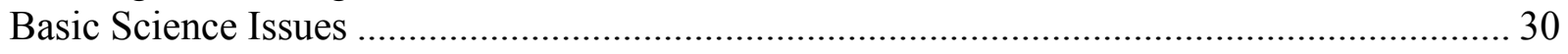

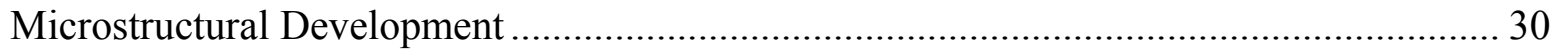

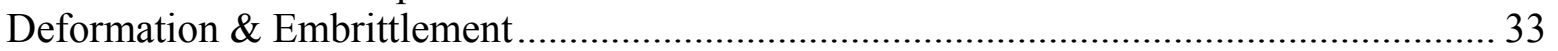

High temperature, time dependent deformation and fatigue ......................................... 34

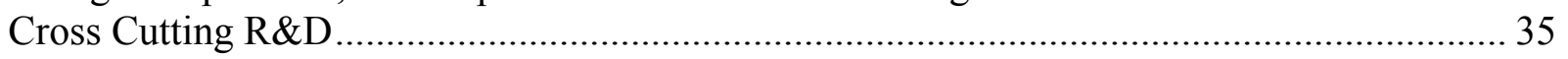

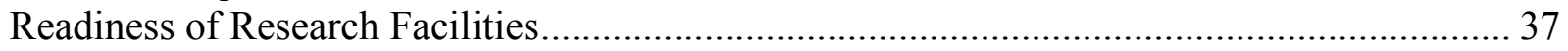

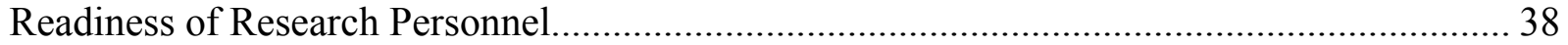

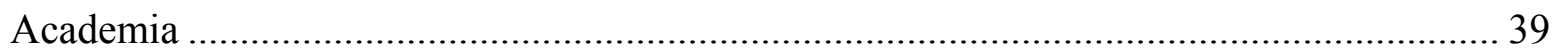

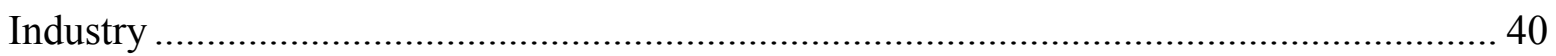

National Laboratories............................................................................................... 41

Reactor Materials Areas not Specifically Addressed......................................................... 42

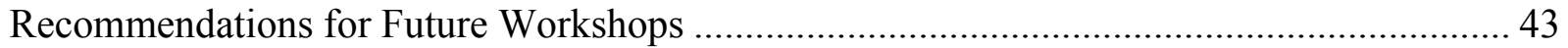

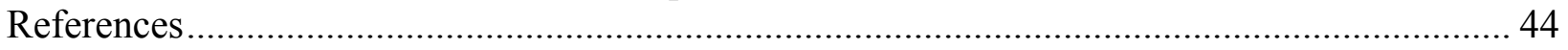




\section{List of Tables}

Table 1. Principal Primary Operating Temperature Ranges for Generation IV Reactor Concepts

Table 2. List of candidate materials and performance issues for low temperature $\left(<\sim 350^{\circ} \mathrm{C}\right)$ applications

Table 3. List of candidate alloys and performance issues for intermediate temperature $\left(\sim 350-650^{\circ} \mathrm{C}\right)$ applications. .46

Table 4. List of candidate materials and performance issues for high temperature applications .46

Table 5. Principal Primary Loop Structural Materials Issues for Generations IV Reactor

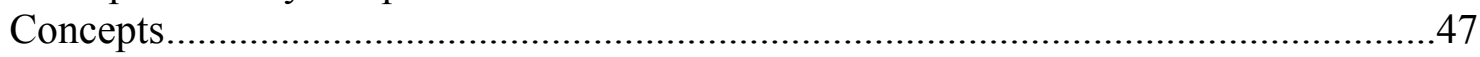

Table 6. Costs for simple plate products (1996 prices) [2] ................................................51 


\section{List of Figures}

Figure 1. Stress-temperature design window for $\mathrm{Nb}-1 \mathrm{Zr}[1]$

Figure 2. Operating temperature windows for various classes of reactor materials alloys. Top figure is for radiation doses up to $10 \mathrm{dpa}$. The second figure is for radiation doses up to $50 \mathrm{dpa}$. The upper and lower bands are temperature ranges where the materials performance may be adequate, but insufficient data currently exists to confirm performance. [1]

Figure 3. Temperature Ranges over which Radiation Damage Occurs .................................54

Figure 4. Relationship between microstructural features and dimensional stability.

Figure 5. Degree production and enrollment in a) BS, b) MS and c) PhD programs in nuclear engineering in the U.S. through 2001 [8].

Figure 6. Increases in (a) undergraduate degrees and in (b) graduate enrollment in the biological/life sciences, physical sciences, mathematics and engineering.

Figure 7. Change in numbers of foreign and U.S. graduate students in (a) physics and astronomy and (b) engineering between 1970 and 2000. 


\section{Summary}

On March 18-21, 2002, the Department of Energy, Office of Nuclear Energy, Science, and Technology (NE) and the Office of Basic Energy Sciences (BES) sponsored a workshop to identify needs and opportunities for materials research aimed at performance improvements of structural materials in higher temperature reactors. The workshop focussed discussion around the reactor concepts proposed as part of the Generation IV Nuclear Energy System Roadmap.

The goal of the Generation IV initiative is to make revolutionary improvements in nuclear energy system design in the areas of sustainability, economics, safety and reliability. The Generation IV Nuclear Energy Systems Roadmap working groups have identified operation at higher temperature as an important step in improving economic performance and providing a means for nuclear energy to support thermochemical production of hydrogen. However, the move to higher operating temperatures will require the development and qualification of advanced materials to perform in the more challenging environment. As part of the process of developing advanced materials for these reactor concepts, a fundamental understanding of materials behavior must be established and the data-base defining critical performance limitations of these materials under irradiation must be developed.

This workshop reviewed potential reactor designs and operating regimes, potential materials for application in high-temperature reactor environments, anticipated degradation mechanisms, and research necessary to understand and develop reactor materials capable of satisfactory performance while subject to irradiation damage at high temperature. The workshop brought together experts from the reactor materials and fundamental materials science communities to identify research and development needs and opportunities to provide optimum high temperature nuclear energy system structural materials. 
Many materials R\&D areas were identified to support development of Generation IV concepts. Based on the discussions at this workshop, the following areas appear to be the most critical for advancing Generation IV concepts.

- Research on advanced ferritic-martensitic and martensitic steels that allow for increased temperature of operation for liquid-metal and supercritical water concepts while improving toughness at lower temperatures. Issues include stability of oxides in ODS materials, basic microstructural and microchemical changes, and phase stability at high temperatures.

- Development and fundamental understanding of radiation performance of refractory alloys, ceramic composites, and coatings for high and very high temperature concepts.

- Research to improve radiation performance of austenitic stainless alloys including resistance to void swelling, embrittlement and stress corrosion cracking.

- Development of new high-temperature superalloys that are tailored for radiation environments (e.g., low nickel contents and controlled phase stability)

- Fundamental and applied understanding of the complexity of radiation damage in engineering alloys, including austenitic, ferritic, ferritic-martensitic, refractory metals, and ceramic materials.

- Fundamental and applied understanding of deformation and creep processes related to flow localization and grain boundaries.

- Fatigue in plants that are expected to load follow.

- Developing design data for nuclear graphite.

Although not specifically considered in this workshop, the attendees did note that significant corrosion related challenges in the areas of supercritical water, lead or lead-bismuth, and molten salts, as well as compatibility of fuels and cladding must be overcome before certain Generation IV concepts are viable.

Several fundamental science issues were identified: 
- The co-evolution of all components of the microstructure, and their roles in the macroscopic response in terms of swelling, anisotropic growth, irradiation creep, and radiation-induced phase transformations should be studied within the of the science of complex systems.

- Displacement damage during irradiation creates a non-equilibrium, structure-chemistry evolution at the nanoscale and alters plasticity, corrosion and fracture processes. Fundamental understanding of these complex, interdependent, radiation-induced material changes is essential to underpin the development of Generation IV reactor systems.

- Key structural performance issues for most irradiated metallic alloys are time-independent embrittlement at low temperatures and time-dependent deformation and cracking at high temperatures. The evolution of non-equilibrium structures and chemistries promote a hardened matrix and lower grain boundary cohesive strengths thereby reducing the tensile stress required for cleavage or intergranular fracture. Advances in modeling and measuring the atomistics of fracture need to be combined with micromechanical models to better elucidate behavior in complex radiation-induced, multi-component nanostructures.

The workshop identified both physical research facilities and human resources as critical to supporting materials research for Generation IV concepts. Of specific note are the lack of a fastspectrum irradiation facility and the expected near-term retirements of a significant number of experts without sufficient young scientists in training to replace the senior faculty, scientists, and engineers.

To control the workshop scope to a manageable level, the workshop did not address all of the issues that significantly weigh on the choice of materials for Generation IV systems.

Specifically, the following items relative to structural materials were not addressed in detail:

- Chemical compatibility and corrosion issues

- Welding and joining

- Fuels, fuel-cladding compatibility, and fuel-recycle system compatibility

- Materials to minimize loss in recycle systems 
- Material availability, cost, fabricability, joining technology

- Safety and waste disposal aspects (decay heat, etc.)

- Nuclear properties (neutron economy, solute burnup, etc.)

All of these issues play a critical role in determining if reactor concepts can be operated safely and reliably and at a reasonable cost. Because many of the proposed Generation IV concepts operate in unique coolants (e.g. lead, lead-bismuth, supercritical water, molten salt), research and development will be required to establish materials that can operate in these environments.

This workshop proved to be a useful initial discussion about the materials aspects of Generation IV nuclear energy systems. Because Generation IV reactor systems were not well enough defined at the time of the workshop to identify specific operating environment, the workshop took a rather broad view of materials issues. At the completion of the Generation IV Roadmap, the number of concepts being considered will be fewer than those considered at this workshop. Future workshops should aim to discuss a narrower issue in greater technical depth. Possible topics for future workshops include:

- Coolant specific corrosion and environmental cracking issues relative to specific Generation IV concepts (e.g., in lead-base, molten-salt, or supercritical water coolants)

- Materials to minimize process loss in fuel recycle systems

- Fuel development for specific Generation IV systems (e.g., nitride fuel development)

Compared to our knowledge of materials used in current light water reactors, the knowledge of in-reactor degradation of the materials being considered for Generation IV applications is significantly lacking. The demands of Generation IV are enormous, in terms of strength, toughness, resistance to corrosion, and dimensional stability, especially considering the synergistic operation of factors that stress the material and the associated failure mechanisms. If in the early 1960s reactor materials experts were asked to predict the problems that later occurred with $\mathrm{UO}_{2}$ fuel, Zircaloy cladding, pressure vessel steels, stainless steels, and other nuclear energy system materials, they would have been unable to even conceive of the problems, let alone 
predict the outcome. This is especially true for complicated failure mechanisms such as irradiation-assisted stress corrosion cracking, which involve the synergistic interaction of various factors or the complex long term evolution of damage in pressure vessel steels. We are likely to discover similar failure mechanisms as we explore the extreme operation conditions of Generation IV reactors. 


\section{Workshop}

This report summarizes the discussions at the March 18-21 "Workshop on Higher Temperature Reactor Materials" sponsored by the Department of Energy Office of Nuclear Energy, Science, and Technology (NE) and the Office of Basic energy Sciences (BES) held in La Jolla, Ca. The report is based on the discussions of the technical experts who participated in the workshop, as summarized by the working group chairs. The workshop report is not based on an extensive search of the literature but rather on the expert opinion of the participants.

\section{Participants}

The following are the workshop participants.

\begin{tabular}{|l|l|}
\hline \multicolumn{1}{|c|}{ Name } & \multicolumn{1}{c|}{ Organization } \\
\hline Allen, Todd & ANL \\
\hline Anghaie, Samim & University of Florida \\
\hline Ardell, Alan & University of California-Los Angeles \\
\hline Arsenault, Dick & University of Maryland \\
\hline Boutard, Jean-Louis & CEA/Saclay \\
\hline Bruemmer, Steve & PNNL \\
\hline Cole, Jim & ANL \\
\hline Crawford, Doug & ANL \\
\hline Davidson, David & Southwest Research Institute (Retired) \\
\hline Edwards, Dan & PNNL \\
\hline Elmer, John & LLNL \\
\hline Ennis, Philip & FZJ Juelich \\
\hline Garner, Frank & PNNL \\
\hline Greene, Charles & NRC \\
\hline Grossbeck, Martin & ORNL \\
\hline Hansen, Linda & ANL \\
\hline Henager, Chuck & PNNL \\
\hline Kassner, Michael & BES/Oregon State University \\
\hline King, Wayne & LLNL \\
\hline Lauron, Carolyn & NRC \\
\hline Lineberry, Mike & ANL \\
\hline MacDonald, Phil & INEEL \\
\hline Maloy, Stuart & LANL \\
\hline
\end{tabular}




\begin{tabular}{|l|l|}
\hline \multicolumn{1}{|c|}{ Name } & \multicolumn{1}{c|}{ Organization } \\
\hline Mansur, Lou & ORNL \\
\hline Martin, Georges & CEA/Saclay \\
\hline McMahon, Charles & University of Pennsylvania \\
\hline Miller, Tom & DOE-NE \\
\hline Motta, Arthur & Penn State University \\
\hline Murty, KL & North Carolina State University \\
\hline Nanstad, Randy & ORNL \\
\hline Nelson, Larry & GE \\
\hline Nunez, Luis & ANL \\
\hline Odette, Bob & University of California-Santa Barbara \\
\hline Panayotou, Nick & Knolls Atomic Power Laboratory \\
\hline Perez-Prado, Teresa & CENIM \\
\hline Rehn, Lynn & ANL \\
\hline Rittenhouse, Phil & Technology Insights \\
\hline Rosen, Bob & Defense Nuclear Facilities Safety Board \\
\hline Shack, Bill & ANL \\
\hline Shenoy, Arkal & General Atomics \\
\hline Sickafus, Kurt & LANL \\
\hline Simonen, Ed & PNNL \\
\hline Snead, Lance & ORNL \\
\hline Southworth, Finis & INEEL \\
\hline Stoller, Roger & ORNL \\
\hline Sullivan, Ted & NRC \\
\hline Ukai, Shigharu & JNC \\
\hline Versluis, Rob & DOE-NE \\
\hline Was, Gary & University of Michigan \\
\hline Wilson, Ian & Westinghouse \\
\hline Wirth, Brian & LLNL \\
\hline Wolfer, Bill & LLNL \\
\hline Zinkle, Steve & ORNL \\
\hline
\end{tabular}

\section{Background}

On March 18-21, 2002, the Department of Energy, Office of Nuclear Energy, Science, and Technology (NE) and the Office of Basic Energy Sciences (BES) sponsored a workshop to identify needs and opportunities for materials research aimed at performance improvements of 
structural materials in higher temperature reactors. The workshop focussed discussion around the reactor concepts proposed as part of the Generation IV Nuclear Energy System Roadmap.

The goal of the Generation IV initiative is to make revolutionary improvements in nuclear energy system design in the areas of sustainability, economics, and safety and reliability. The Generation IV Nuclear Energy Systems Roadmap working groups have identified operation at higher temperature as an important step in improving economic performance and providing a means for nuclear energy to support thermochemical production of hydrogen. However, the move to higher operating temperatures will require the development and qualification of advanced materials to perform in the more challenging environment. As part of the process of developing advanced materials for these reactor concepts, a fundamental understanding of materials behavior must be established and the data-base defining critical performance limitations of these materials under irradiation must be developed.

This workshop reviewed potential reactor designs and operating regimes, potential materials for application in high-temperature reactor environments, anticipated degradation mechanisms, and research necessary to understand and develop reactor materials capable of satisfactory performance while subject to irradiation damage at high temperature. The workshop brought together experts from the reactor materials and materials science communities to identify research and development needs and opportunities to provide optimum high temperature nuclear energy system structural materials.

\section{Generation IV Initiative}

Beginning in 2000, the United States proposed to the Generation IV International Forum (GIF) that a technology roadmap be prepared to guide the Generation IV effort. The GIF is a group of ten countries that have joined together to advance concepts for a number of next-generation nuclear energy systems that can be licensed, constructed, and operated in a manner that will provide competitively priced and reliable energy products, while satisfactorily addressing 
nuclear safety, waste, proliferation and public perception concerns. The GIF agreed to support the preparation of a technology roadmap, and the roadmap became the focal point of their efforts.

As preparations for the technology roadmap began, it was necessary to establish goals for Generation IV nuclear energy systems. Eight goals for Generation IV are defined in three broad areas of economics, safety and reliability, and sustainability. Economics goals focus on creating a competitive life cycle and minimizing energy production costs and financial risk. Safety and reliability goals focus on safe and reliable operation, investment protection, and essentially eliminating the need for off-site emergency response. Sustainability goals focus on fuel utilization, waste management, and proliferation resistance.

The Generation IV initiative (http://gen-iv.ne.doe.gov/ ) has evaluated nuclear energy system concepts against the Generation IV Goals. The systems can be classified in four broad groups: water-cooled, gas-cooled, liquid metal-cooled, and non-classical systems. The concepts being evaluated at the time of this workshop are listed in Table 1. For those concepts that appear to have the best chance of meeting the Generation IV goals, detailed research and development (R\&D) plans will be developed. The output of this workshop will support both concept selection and development of the R\&D plans.

\section{Design Needs-Mission Performance, Safety, Operability}

Proper choices of cladding and structural materials are essential for the safe and reliable operation of any Generation IV system. The survivability of fuel cladding (prevention of cladding breach) must be ensured and predictable. Therefore, the wastage and strain of the cladding under all operating conditions must be understood. Cladding wastage can be caused by corrosion of the cladding by the coolant or chemical interaction between fuel or fission products. Cladding strain can be caused by fission gas or coolant pressurization, swelling of constrained components, or fuel cladding mechanical interaction. Structural materials must maintain 
adequate strength, toughness and ductility, must have corrosion rates that are acceptable, and must have adequate dimensional stability with regards to swelling and creep.

A wide range of structural materials are candidates for Generation IV applications, including austenitic stainless steels, Ni-and Fe-based super alloys, various grades of ferritic and ferriticmartensitic steels, oxide-dispersion-strengthened austenitic or ferritic steels, conventional hightemperature refractory alloys (based on $\mathrm{V}, \mathrm{Nb}, \mathrm{Ta}, \mathrm{Cr}$, Mo and $\mathrm{W}$ ), and various composite materials $(\mathrm{C} / \mathrm{C}, \mathrm{SiC} / \mathrm{SiC}$, metal-matrix composites, etc.). Numerous factors must be considered in the selection of structural materials, including:

- unirradiated mechanical and thermophysical properties

- radiation effects (degradation of properties)

- chemical compatibility and corrosion issues

- material availability, cost, fabricability, joining technology

- $\quad$ safety and waste disposal aspects (decay heat, etc.)

- nuclear properties (neutron economy, burnup, etc.)

The workshop focused on assessing the first two criteria in this list, with particular emphasis on how these issues impact the allowable operating temperature and dose limits. Cursory information was also presented on the important area of chemical compatibility, but to maintain a manageable workshop scope, chemical compatibility was not a major focus of the workshop.

Because of the wide range of concepts being evaluated in the Generation IV Roadmap and the significant differences in the design maturity, the materials needs are not easily classified. To make recommendations to the Roadmap, the workshop participants divided the proposed concepts into four groups, based generally on the primary temperature range in which the concepts operate. These divisions are shown in Table 1. 


\section{Design Approach}

Several factors define the allowable operating temperature window for structural and cladding alloys in a nuclear reactor. The lower operating temperature limit in all body-centered cubic (bcc) and many face-centered cubic (fcc) alloys is determined by radiation embrittlement (decrease in fracture toughness), which is generally most pronounced for irradiation temperatures below $\sim 0.3 \mathrm{~T}_{\mathrm{M}}$ where $\mathrm{T}_{\mathrm{M}}$ is the melting temperature. Radiation-induced loss in toughness in bcc alloys at low temperatures $\left(<0.3 \mathrm{~T}_{\mathrm{M}}\right)$ is generally pronounced even for doses below $1 \mathrm{dpa}$. The loss of ductility in fcc materials is somewhat sensitive to damage rate. Some components that undergo a limited degree of radiation embrittlement may still be used in applications where the expected stress is small. The lower operating temperature limit for $\mathrm{SiC} / \mathrm{SiC}$ composites will likely be determined by radiation-induced thermal conductivity degradation, which becomes more pronounced in ceramics with decreasing temperature. In addition, amorphization of SiC (which occurs at irradiation temperatures $<150^{\circ} \mathrm{C}$ ) sets a firm lower temperature limit due to the $11 \%$ volume swelling.

The upper operating temperature limit of structural materials is determined by one of four factors, all of which become more pronounced with increasing exposure time: 1) thermal creep (grain boundary sliding or matrix diffusional creep), 2) high temperature He embrittlement of grain boundaries, 3) cavity swelling or anisotropic growth (particularly important for $\mathrm{SiC}$ and graphite, respectively), or 4) coolant compatibility/corrosion issues. In many cases, the upper temperature limit will be determined by coolant corrosion/ compatibility rather than by thermal creep or radiation effects. Based on existing irradiation data, void swelling is not anticipated to be a major concern in any of the bcc alloys up to damage levels in excess of $100 \mathrm{dpa}$, although further data are needed. Radiation-enhanced recrystallization (potentially important for stressrelieved Mo and $\mathrm{W}$ alloys) and radiation creep effects (due to a lack of data for the refractory alloys and $\mathrm{SiC}$ ) need to be investigated.

An example of a stress-temperature design window is given in Figure 1 for $\mathrm{Nb}-1 \mathrm{Zr}$ [1]. The high-temperature limit is defined by thermal creep, the low-temperature limit by radiation 
embrittlement, and the upper stress limit by strength. For a specific application, coolant compatibility would also need to be factored into the analysis.

Figure 2 summarizes the operating temperature windows (based on thermal creep and radiation damage considerations) for the several structural materials considered in the workshop [2, 3]. Additional temperature restrictions associated with coolant compatibility need to be analyzed for specific reactor concepts. The specific values of the operating temperatures need to be combined with compatibility data for the candidate coolants to determine if the temperature window is reduced due to corrosion issues. As noted earlier, the minimum operating temperature for $\mathrm{SiC} / \mathrm{SiC}$ is based on radiation-induced thermal conductivity degradation. The high temperature limit is based on thermal creep for all of the materials except SiC (void swelling was the limiting factor for $\mathrm{SiC})$. A Stage II (steady-state) creep deformation limit of $1 \%$ in $1000 \mathrm{~h}\left(3 \times 10^{-9} \mathrm{~s}^{-1}\right.$ steady-state creep rate) for an applied stress of $150 \mathrm{MPa}$ was used as an arbitrary metric for determining the upper temperature limit associated with thermal creep. Design-specific creep data would obviously be used to establish the temperature limits for longer times and lower stresses in several of the candidate materials.

\section{Interaction between Radiation Damage and Microstructure}

Radiation damage mechanisms occur in temperature ranges roughly defined by the homologous temperature, or fraction of the melting temperature. Figure 3 demonstrates the relationships. At low temperature, embrittlement due to radiation damage or due to the build-up of embrittling transmutation gases such as $\mathrm{He}$ and ${ }^{3+} \mathrm{H}$ may cause a loss of toughness at low temperature. At intermediate temperatures, radiation creep and void swelling cause dimensional instabilities that must be understood for proper reactor operation. In addition, high-temperature helium embrittlement is likely unless the helium is properly managed. Reactor designs that increase operating temperatures above $\sim 600^{\circ} \mathrm{C}$ will need to consider effectively strengthened alloys with higher melting temperature metals for structural components. Using these higher melting temperature alloys does not eliminate the possibility of similar radiation damage mechanisms as 
those found in construction materials (i.e., Fe- and Ni-base alloys) of current generation reactors. All of the higher temperature alloys need to be investigated to understand the effect of radiation damage and define performance limits in Generation IV reactor environments.

The changes in mechanical properties and dimensional stability in reactor components are caused by the development of microstructural features during irradiation. The complex relationships are illustrated in Figure 4. As an example, void swelling can cause unacceptable changes in dimension in reactor components. The density and size distribution of the voids is closely linked to the development of the dislocation loop structure as both voids and dislocations compete for point defects. Both void and dislocation development are affected by radiation-induced segregation and vice versa. The changes in composition in the area near the void and dislocations affect their growth and can induce precipitation. Similar complex relationships exist among all microstructural features and among microstructural features and bulk properties (e.g., strength, dimensional stability, ductility and toughness). In each of the following sections, the R\&D challenges will be outlined for specific temperature regimes. Because of the strong relationship between bulk properties and microstructural features, each section will contain a description of the R\&D challenges for both the bulk properties and the microstructure.

\section{Lower Temperature Reactor Issues $\left(\mathrm{T}<350^{\circ} \mathrm{C}\right)$}

This section discusses the materials R\&D needs for components operating at temperatures less than $350^{\circ} \mathrm{C}$. As shown in Table 1 , temperatures less than $350^{\circ} \mathrm{C}$ are typically associated with water reactors (LWRs).

Materials issues for the low-temperature, advanced light-water-reactor (LWR) designs are far and away the best understood and manageable among the Generation IV concepts. Problems that are anticipated directly reflect economic and safety concerns being dealt with for existing Generation II plants (see Table 2). 
High radiation levels in a reactor core produce changes in iron- and nickel-base austenitic stainless alloys leading to extensive hardening, a reduction in uniform ductility, and an increased susceptibility to intergranular stress corrosion cracking (SCC). This cracking process, called irradiation-assisted stress corrosion cracking (IASCC), is a serious concern for both boiling water reactors (BWRs) and pressurized water reactors (PWRs). Stainless steel components can become susceptible to cracking at doses less that $10 \%$ of the expected end-of-life dose and the likelihood of failure may increase with increasing service exposure. Susceptibility to IASCC is clearly linked to radiation-induced changes in the alloy microstructure and microchemistry, but fundamental understanding of controlling mechanisms has been elusive.

More extensive material changes can occur in components where gamma heating leads to temperatures greater than $\sim 330^{\circ} \mathrm{C}$. Void swelling potentially becomes a life-limiting issue at these higher temperatures particularly for PWR designs where extremely high doses ( $>80 \mathrm{dpa})$ are reached. Swelling is not significant at temperatures below $300^{\circ} \mathrm{C}$ due to the difficulty of nucleating and growing voids. Void nucleation and growth depend sensitively on the alloy composition, solute additions and He production rate. Radiation-induced precipitation can also occur at these higher temperatures in the matrix and at grain boundaries when the solubility limit for a particular solute is reached due to RIS. Matrix precipitation can further harden the alloy, while grain boundary phases can promote intergranular embrittlement in some cases.

The microstructural development of austenitic iron- and nickel-base alloys under irradiation in the $270-350^{\circ} \mathrm{C}$ range is reasonably well known, but not always well understood. At temperatures below $300^{\circ} \mathrm{C}$, the primary radiation-induced microstuctural components are small dislocation loops that promote hardening. The dislocation microstructure has been reasonably well characterized but poorly understood and not effectively modeled. Outstanding issues involve understanding the process of loop nucleation and the loop character. Radiation-induced segregation (RIS) occurs throughout the LWR temperature range and can cause significant composition variations at strong sinks such as grain boundaries. While segregation of the major alloying elements $\mathrm{Fe}, \mathrm{Cr}, \mathrm{Ni}$ is fairly well characterized and can be reasonably well modeled, the 
understanding of the behavior of minor elements that are believed to migrate as interstitials is poor and modeling capabilities are inadequate.

While improved mechanistic understanding and alloy development show potential for new austenitic alloys for advanced LWR applications, ferritic/martensitic alloys also have demonstrated better microstructure response while providing good strength with moderate corrosion resistance. These alloys are more resistant to swelling because of the long incubation period for void nucleation. Much of their recent development has been focused on improvements in fracture toughness after irradiation. However, there is very little data or understanding of other potentially important processes such as RIS, dislocation microstructure evolution or IASCC resistance under LWR conditions.

Significant levels of irradiation creep and associated stress relaxation can accumulate at LWR temperatures and can be accelerated by reactor transients in some cases. The current successful use of austenitic stainless steels suggests that they can be similarly applied in Generation IV reactors as long as the stress levels and duty cycles are comparable. Additional data is needed to determine the potential level of irradiation creep for materials other than austenitic stainless steels, and on transient effects in all materials. Current data indicates that the steady-state irradiation creep rate in ferritic-martensitic steels may be as little as $20 \%$ that of austenitic stainless steels. This needs to be confirmed, and transient creep rates need to be evaluated for the use of these steels as core structural materials.

Fatigue is not a significant issue in reactor internal components in current designs, although it must be considered when evaluating reactor piping. Potential sources of fatigue, such as flowinduced vibration are controlled or eliminated by design. Since LWRs in the U.S. are typically used to provide base-load power, major thermo-mechanical cycles are primarily associated with reactor startup and shutdown and the number of cycles is relatively small. If future plants are used for load-following, as is the case in some countries in Europe, the number of cycles may increase dramatically. In such a case, a more detailed design and material specific analysis for the impact of fatigue will be required. However, it is likely that existing fatigue design rules 
based on concepts such as traditional Wohler (S-N) curves or the more modern Coffin-Manson equation (an empirical curve of cyclic strain vs. lifetime) will be adequate for the application of most Generation IV reactor components that operate below $350^{\circ} \mathrm{C}$.

As long as a component is expected to experience only a few hundred cycles before being taken out of service, the realm is that of low-cycle fatigue, and the lifetime can be predicted using the empirical Coffin-Manson equation. However, within the past few years, fatigue machines operating at $20 \mathrm{kHz}$ have been used to re-examine the concept of the endurance limit, and the findings indicate that there may be no endurance limit for failures in the very high cycle range. When new nuclear plants are designed, it will be important to incorporate this new knowledge for characterizing fatigue into the design and lifetime prediction process.

The effects of the reactor exposure environment and of radiation on fatigue in reactor internals warrant further research. Radiation-induced segregation could impact fatigue crack initiation and crack growth in a fashion similar to their impact on IASCC. The combined effects of RIS, radiation-induced hardening of the matrix, and the effects of water chemistry (e.g. due to radiolysis) could give rise to unexpected levels of fatigue damage accumulation.

Zirconium-based alloys are used for fuel cladding in all water-based designs and are well suited for use in this temperature range. They provide good corrosion resistance and adequate strength and are not prone to swelling. . With proper alloy design, $\mathrm{Zr}$ alloys might be extended for use at slightly higher temperatures.

The main degradation mechanisms of $\mathrm{Zr}$ alloy cladding are corrosion and hydriding, but for the high temperature and burnup being considered, other mechanisms may become active. In particular, irradiation deformation mechanisms such as creep and growth may again become a consideration, as well as the onset of changes in rates of corrosion mechanisms (breakaway corrosion). The newer Zr alloys such as ZIRLO and M5, have much smaller rates of in-reactor degradation than Zircaloy-4 (meaning lower corrosion rates and lower hydrogen pickup and lower growth rates). At the current burnup limits ( $62 \mathrm{GWd} / \mathrm{t}$ fuel bundle average), these 
advanced alloys show corrosion rates (less than 20-30 micron oxides at the end of life) and irradiation growth rates that, extrapolated to high fluences would be quite tolerable. The uniform corrosion rates in BWR cladding are typically less than in PWR, but in BWRs accelerated localized corrosion (nodular corrosion or shadow corrosion) or hydriding problems are of more concern. Improved cladding (barrier cladding) and hydrogen water chemistry have helped address some of these problems

The very extensive experience base that currently exists, predicts good cladding behavior up to $10 \mathrm{~s}$ of dpas and up to 5 years in-reactor under normal operation. The safety of fuel cladding at high burnup to accidents such as a reactivity insertion accident (RIA), a loss of coolant accident (LOCA) and an anticipated transient without scram (ATWS) has been recently evaluated and is now undergoing confirmatory research. Extrapolation to a factor of two is foreseeable within the current database. The effect of long-term (to $100 \mathrm{dpa}$ ) irradiation-induced microstructural changes on in-reactor degradation processes is not well understood. Processes such as precipitate dissolution, amorphization and formation of dislocation structures at high fluences might influence alloy behavior. For example, a transition in growth rates at intermediate fluences has been linked to the development of c-component dislocations, which have in turn been associated with stabilization of these loops by Fe released from precipitates that have undergone amorphization or dissolution.

The investigation of these processes that occur at high doses, coupled with high temperature corrosion testing could form the initial framework for research programs in high burnup, high temperature operation of $\mathrm{Zr}$ alloys.

The reactor pressure vessel remains perhaps the most important safety-related component in a nuclear power plant. Radiation-induced embrittlement of the ferritic steel is a critical concern particularly in the beltline region where long-term exposure to a moderate neutron flux leads to a significant reduction in fracture toughness. Considerable work has been performed establishing an empirical "master curve" approach to model the shift in the ductile-brittle transition temperature (DBTT) in ferritic pressure vessel steels. This research has helped quantify 
radiation-induced property changes and enable effective management of the degradation process. Fundamental links among alloy composition, radiation-induced microstructural evolution and embrittlement have improved alloy specifications and long-term properties. However, research is still needed to further reduce DBTT at higher doses, justify reduction in excess conservatism in reactor design and operation, and qualify remedial actions.

Corrosion and stress corrosion cracking are problems that have not been effectively solved for current LWR systems and remain an issue that must be recognized for Generation IV designs. These environmental degradation problems severely impact the economic operation of plants and, in a few cases, have created safety issues. The recent localized corrosion of the pressure vessel at the Davis Besse plant illustrates how potentially damaging these processes can be. Stress corrosion cracking continues to be a significant issue for nickel-base stainless alloys used for steam generator tubing, pressure vessel head penetrations and dissimilar metal weldments. The decades of LWR experience illustrates the need for underpinning science and the development of new alloys with improved corrosion and stress corrosion resistance in hightemperature water environments.

For low temperature reactors, the following issues are considered the most critical:

- Developing a mechanistic understanding of IASCC

- Determining the extent of void swelling in higher temperature components

- Understanding the complex, composition-dependent microstructural development that occurs in this temperature range

- Determining the feasibility of ferritic-martensitic steels for use in water reactor core internals.

- The microstructural development and associated performance of zirconium alloys for use as fuel cladding to high burn-up

- An understanding of fatigue in plants that load-follow 
Improved radiation- and corrosion-resistant alloys are needed for the envisioned Generation IV water-cooled designs. Evolutionary modifications to current metallic alloys will likely be sufficient to achieve most performance goals. However, focused research and development activities are essential to establish basic understanding of degradation processes and build the necessary database to confirm alloy/component reliability in reactor service. The complex, interdependent evolution of radiation-microstructure and microchemistry must be better understood to produce alloys more resistant to degradation.

\section{Intermediate Temperature Reactor Issues $\left(350^{\circ} \mathrm{C}<\mathrm{T}<600^{\circ} \mathrm{C}\right)$}

This section discusses the materials R\&D needs for components operating at temperatures between $350-600^{\circ} \mathrm{C}$. As shown in Table 1, reactor concepts in this temperature range are supercritical water reactors and liquid metal reactors. Over this temperature range, candidate materials will require higher strength and greater resistance to diffusion-driven processes such as radiation-induced segregation and precipitation, void formation and growth, dislocation loop growth, creep, fatigue and high temperature corrosion and stress-induced corrosion cracking processes. Table 3 lists the prime candidate alloys and the associated performance issues addressed in this section of the report.

The increase in reactor operating temperature and change in coolant environment alters material selection and many performance issues. Detrimental radiation-induced microstructural evolution (swelling and precipitation) and embrittlement severely limits the application of conventional austenitic stainless alloys. However, experimental swelling-resistant austenitic stainless steels have been produced for temperature up to $\sim 600^{\circ} \mathrm{C}$ during testing in advanced reactor programs [4]. Irradiation creep can be very severe in this temperature range for conventional austenitic stainless steels such as AISI-316 or AISI-304, and limits their use under high stresses to $<600^{\circ} \mathrm{C}$. Dispersed oxide precipitates or other second phase particles will be required for austenitic stainless alloys to maintain adequate strength at the upper end of the temperature range. The behavior of the precipitates under irradiation and their dose/temperature evolution is largely 
unknown, as is RIS, void swelling and dislocation microstructure interaction with the precipitates. The impact of an evolving precipitate structure on the dislocation microstructure, void nucleation and growth and RIS to interfaces are critical challenges. Very little data is available on these alloys and fabrication could well become a limiting factor.

At intermediate temperatures, helium diffusion and precipitation under irradiation will become more important than for present-day water reactor operating conditions. In this temperature range, the austenitic alloys pass through their peak in swelling, and at higher temperatures, void swelling will be minimal. The use of solute additions (e.g., Ti to stabilize carbon mobility and oversized substitutional solutes) may promote recombination and delay the onset of swelling so that doses of as much as 100 dpa may be reached before swelling becomes too large to accommodate by design. Helium generated from thermal neutron capture in Ni will migrate to grain boundaries and result in grain boundary bubble embrittlement. Here again, solute additions may be important in trapping He at vacancy-solute clusters to delay the aggregation of He into bubbles. RIS and irradiation-induced precipitation become increasingly important issues. RIS will peak in the $400-500^{\circ} \mathrm{C}$ range, while near the upper end of the range the high concentration of thermal vacancies will suppress RIS. The dislocation loop density will decrease sharply and the loop size will coarsen throughout the temperature range. At the upper end of the range, the microstructure should resemble an annealed condition with few loops and a low network density, with precipitation processes becoming increasingly important.

In this temperature regime, types and populations of all microstructure features change quickly with temperature. Little is understood about the complex interactions that could occur between microstructure features such as dislocations, voids/bubbles, RIS, precipitates when the characteristics of each is a very sensitive function of temperature. The interplay between these features and their relative sensitivities to temperature will be important to understand for austenitic Fe- and Ni-based alloy systems to be applied in this temperature regime. (see Figure 4)

The limitations with austenitic stainless alloys, especially void swelling, make the more radiation-tolerant ferritic-martensitic (F-M) steels attractive choices for high-dose core internal 
components. Ferritic-martensitic alloys provide the potential to achieve doses above 200 dpa due to their inherent resistance to swelling. Primary concerns for these steels are the same as for pressure vessel steels, i.e., radiation or thermal aging effects on toughness and the DBTT. The creep rate tends to be significantly lower for ferritic and F-M steels than for austenitic stainless steels, but creep begins to become an issue at the top end of this temperature range $\left(600^{\circ} \mathrm{C}\right)$. Recently, a class of ferritic and F-M steels have been developed in which a very fine ( $\sim 1$ to $4 \mathrm{~nm}$ diameter) oxide particles has been dispersed. The best of these oxide-dispersion strengthened (ODS) alloys have been shown to maintain this fine dispersion under thermal creep conditions of elevated temperature and stress. If this behavior is maintained under irradiation, the ODS steels may increase the upper temperature limit of the F-M steels by 100 to $200^{\circ} \mathrm{C}$, and increase the operating stress limit in the 350 to $600^{\circ} \mathrm{C}$ temperature range. Limited irradiation data on a French ferritic ODS steel up to $600^{\circ} \mathrm{C}$ indicates that Chi phase formation can lead to crack nucleation at low plastic strains. This same alloy also showed evidence of oxide particle dissolution after irradiation to $80 \mathrm{dpa}$ at $\sim 500^{\circ} \mathrm{C}$. There is virtually no experimental data on RIS in these systems.

Irradiation-assisted corrosion and IASCC are critical unknowns for the supercritical water reactor concept even though corrosion-resistant ferritic-martensitic alloys have been developed for fossil plants. Radiolysis effects may influence the base aggressiveness of the supercritical water environment with respect to corrosion and environment-induced cracking processes. In addition, radiation-induced material changes may alter properties and promote degradation in all of the possible alloy choices. The long-term corrosion and stress corrosion cracking behavior of ferritic-martensitic steels in lead-based coolants and molten salt is similarly, poorly known. These represent important areas of research requiring long-term tests on irradiated materials in supercritical water environments.

Both solid-solution and precipitate-strengthened nickel-base alloys have also been investigated in this temperature range. Solid solution alloys should have adequate strength and creep resistance up through the middle portion of the temperature range, and precipitation-hardened alloys are well suited to the upper end of the range. However, high He production and precipitation - 
induced grain boundary embrittlement will likely limit application in this temperature range to low ( $<20 \mathrm{dpa}$ ) dose applications. The high nickel content leads to the formation of high levels of helium from nuclear transmutation reactions initiated by thermal neutrons. Even relatively modest amounts of helium can significantly reduce ductility in these materials and may accelerate fatigue crack growth. Some nickel-based superalloys may be more resistant to embrittlement and creep deformation, but will likewise be limited by the formation of helium. Many of these alloys are also limited by softening and creep under irradiation above $500^{\circ} \mathrm{C}$, and by the formation of brittle second phases. Nevertheless, precipitate stability and RIS in this system is not well understood, even in this low dose range.

Many of the Generation IV reactor designs produce less power than current LWRs and this lower power output may increase the likelihood that they will be used in a load-following mode. This would require more attention be given to fatigue and creep-fatigue interactions in this temperature regime. The required analysis methodology will depend on the cyclic loading frequency, absolute stress level, and temperature. The potential affect of RIS and exposure to the reactor coolant must also be considered. Thus, the analysis will be design and material specific. A reasonable database exists only for the austenitic stainless steels, and to a lesser extent, some of the advanced ferritic and F-M steels. Irradiation data is lacking on other potential alloy systems such as the ODS steels and high nickel alloys.

For intermediate temperature reactors, the following issues are considered the most critical:

- Research on advanced ferritic-martensitic and martensitic steels that allow for increased temperature of operation for liquid-metal and supercritical water concepts and improving toughness at lower temperatures. Issues include stability of oxides in ODS materials, basic microstructural and microchemical changes, and phase stability at high temperatures.

- Understanding the complex, composition-dependent microstructural development that occurs in this temperature range.

- Corrosion in supercritical water and lead-based coolants.

- Development of austenitic alloys resistant to swelling to very high dose. 


\section{High Temperature Reactor Issues $\left(600^{\circ} \mathrm{C}<\mathrm{T}<900^{\circ} \mathrm{C}\right)$}

This section discusses the materials R\&D needs for components operating at temperatures between $600-900^{\circ} \mathrm{C}$. As shown in Table 1, gas reactors, molten-salt reactors, and lead-cooled metal reactors are expected to operate in this temperature range.

The ability to obtain higher thermal efficiency by increasing operating temperatures is limited by the range of possible structural materials. Table 4 summarizes candidate materials and some of the issues that may limit their application. Above $600^{\circ} \mathrm{C}$, the thermal mechanisms, rather than irradiation-induced mechanisms, dominate the behavior of most of the metallic alloy systems of interest. For example, the dominant creep mechanism becomes thermal, rather than irradiation creep. Conventional austenitic, ferritic, or ferritic-martensitic (F-M) steels cannot be used above $600^{\circ} \mathrm{C}$ with any significant level of applied stress. The best oxide-dispersion strengthened (ODS) F-M steels may have adequate creep strength for temperatures to $\sim 800^{\circ} \mathrm{C}$, but, except for experimental heats, this has yet to be demonstrated. Moreover, there are essentially no data on the radiation stability of the oxide dispersion that is critical to the performance of these materials. The radiation- and aging-induced phase stability of these alloys will be critical to maintaining acceptable creep resistance, toughness, and a low DBTT. These ODS materials are promising but remain the subject of ongoing research. For example, a significant level of research is needed to understand the issues related to the oxide nanocluster formation and stability during the process of alloy fabrication by mechanical alloying and extrusion, and the mechanisms by which they influence high temperature plasticity.

The primary alternatives are materials such as precipitate-strengthened iron or nickel-base superalloys or refractory alloys of molybdenum, niobium, and tantalum. These are under consideration because of their high strength and good high-temperature creep resistance. Unfortunately, little is known about the microstructural development of either alloy class under irradiation at these temperatures. The degree of radiation-induced segregation (RIS) is not known but will likely be minimal due to the very high concentration of thermal vacancies that will tend to mitigate the effects of radiation-induced defect flow. The dislocation microstructure is 
likewise expected to be essentially free from irradiation-induced dislocation loops due to the instability of loops at such high temperatures. However, the effect of extremely high densities of small precipitates on both RIS and the dislocation microstructure in this temperature range is relatively unknown and little if any data exist. The stability of the precipitates themselves and their evolution with dose and temperature are unknown as well. Finally, the practical use of the refractory alloys is challenged by inherent toughness problems, limited understanding of radiation-induced material changes, a high sensitivity to oxygen-impurity pickup that can lead to further embrittlement, and cost.

While the nickel-base alloys may be used in components that are not exposed to neutrons, any in-core applications would have to be limited to very low doses due to transmutant helium production. RIS may further limit their nuclear applications by contributing to the formation of brittle phases with the potential for associated cracking. The upper temperature limit for out-ofcore applications may be set by the thermal stability of the $\gamma^{\prime}$ phase that provides their creep strength. There is currently little creep or fatigue data in this temperature range for the refractory alloys. Substantial research is required before their successful use can be anticipated. All issues related to microstructural stability and its impact on the accumulation of creep and fatigue damage need to be explored thermally as well as under irradiation, e. g. dislocation evolution, phase stability, and the possible impacts of enhanced diffusion- or radiation-induced segregation.

The importance of creep-fatigue interactions may increase at these high temperatures in components subjected to cyclic loads; little relevant data is available for any of the candidate materials. Creep rupture behavior of essentially all metals and alloys will be strongly influenced by the production of transmutant helium which will be mobile at high temperatures and is likely to accumulate in bubbles at grain boundaries. The level of concern is proportional to the helium production, which is highest in the nickel-base alloys. However, here again, there is not sufficient data to rank the candidate materials with respect to this issue.

Assuming that a reactor pressure vessel will be required for most Generation IV designs, the selection of an appropriate material for use in this high-temperature, thick-walled component 
will be difficult. Ferritic-martensitic steels may meet the strength requirements below about $700^{\circ} \mathrm{C}$. However, they will be sensitive to radiation- and aging-induced degradation of fracture toughness. The higher operating temperature may limit the radiation-induced shift in the DBTT, but more experimental data and mechanical analysis is required before a pressure vessel material can be recommended in this temperature range. This analysis should include a design-specific review of anticipated accident conditions.

Compatibility between structural materials and coolants is a significant issue at these elevated temperatures. Corrosion and environmentally-induced cracking issues must be evaluated for the lead-cooled and molten-salt fueled reactor designs. Experience with $\mathrm{Pb}$ or $\mathrm{Pb}$ - $\mathrm{Bi}$ suggests that ferritic-martensitic steels may have adequate corrosion resistance depending on protective film formation, however more work is needed to establish this behavior. For the novel molten-salt fueled design, little is known concerning corrosion behavior in these aggressive fluoride salts. Although corrosion is not a primary issue for gas-cooled reactors, the impact of residual oxygen must be considered if oxygen-sensitive structural materials (such as the refractory alloys or SiC) are used.

At the upper end of this temperature range, ceramic composites may become a viable option for specific structural components. The only system that has been studied in some detail is SiC-SiC composites, for which a limited amount of radiation effects data is available because of the interest in this material by the fusion program. While the overall strength of the composite is related to the fiber strength, the strength and toughness under load depend on the integrity of the fiber-matrix interface. These interfaces can be degraded by radiation or environmental exposure, which leads to debonding. Fatigue data on the composites is preliminary but promising, particularly in comparison with monolithic ceramics. However, differential swelling between the fiber and matrix components can give rise to internal stresses as neutron exposure increases, leading to cracking at the fiber-matrix interface. For low oxygen partial pressures, crack growth is limited by either irradiation $\left(\mathrm{T}<1200^{\circ} \mathrm{C}\right)$ or thermal creep $\left(\mathrm{T}>1200^{\circ} \mathrm{C}\right)$ of the fibers. Significant levels of helium will be produced by nuclear transmutation in $\mathrm{SiC}$, and this will exacerbate creep rupture behavior. 
Graphite will be used as a neutron moderator and structural material in most thermal spectrum gas-cooled reactor designs. In spite of a lengthy history of research and use of graphite by the nuclear industry around the world, there is not now a qualified source for nuclear grade graphite in the U.S. Graphite is a composite material made from a coke filler, coal tar pitch binder and petroleum impregnating pitch. The material is formed, baked, impregnated and re-baked before being heated to temperatures in excess of $2500^{\circ} \mathrm{C}$ during the final phase of manufacture. Consequently, the graphite microstructure is complex, with both binder and filler derived graphite regions and porosity. Moreover, the method of forming (extrusion, molding or pressing) imparts structural anisotropy to the artifact because the filler coke and internal porosity are aligned during forming, i.e., the material develops texture.

The lack of design data for nuclear graphite is a critical issue. The graphite grades used in the past for reactors in Europe and the U.S.A. are no longer available. Moreover, these graphite grades cannot easily be recreated since the sources of filler coke (critical to graphite behavior) are no longer available. Consequently, new cokes and graphite grades will require qualification and an adequate design database must be developed. Developing and carrying out a program for qualification of nuclear graphite needs to be a near-term priority if gas-cooled reactor research is going to be seriously pursued. Other fundamental research needs for graphite include: characterizing primary damage in graphite, determining the fate of transmutant helium and its impact on microstructure evolution, and the effect of high doses of radiation on fracture toughness.

The dimensional changes occurring in the graphite during operation give rise to internal stresses. These stresses may be relieved by irradiation creep at temperatures far below those at which thermal creep is significant. Stress relaxation by irradiation creep has been studied and the mechanism is reasonably well understood. However, there is a paucity of relevant data for currently available graphite. Neutron irradiation damage causes a rapid initial increase in the strength and modulus of the graphite. However, structural changes that occur at higher damage doses eventually cause a reduction in strength and stiffness. Thermal properties such as thermal 
conductivity are also markedly affected by neutron irradiation. The displacement of carbon atoms from the graphite basal planes adds phonon scattering centers that in turn markedly reduce the phonon mean free path. Consequently, the thermal conductivity rapidly falls, by as much as an order of magnitude, at relatively small damage doses. Moreover, the effect is temperature dependent because at higher irradiation temperatures the displaced carbon atoms are more mobile and can recombine with lattice vacancies. Thus, the extent of thermal conductivity degradation is more marked at lower irradiation temperatures.

For high temperature reactors, the following issues are considered the most critical:

- Research on advanced ferritic-martensitic and martensitic steels that allow for increased temperature of operation for liquid-metal and supercritical water concepts and improving toughness at lower temperatures. Issues include stability of oxides in ODS materials, basic microstructural and microchemical changes, and phase stability at high temperatures.

- Understanding the complex, composition dependent microstructural development that occurs in this temperature range.

- Development and fundamental understanding of radiation performance of refractory alloys, ceramic composites, and coatings for high temperature concepts.

- Qualification of an appropriate material for use as a high-temperature, thick-walled pressure vessel.

- Developing design data for nuclear graphite.

\section{Very High Temperature Reactor Issues $\left(900^{\circ} \mathrm{C}<\mathrm{T}\right)$}

This section discusses the materials R\&D needs for components operating at temperatures greater than $900^{\circ} \mathrm{C}$. As shown in Table 1 , temperatures greater than $900^{\circ} \mathrm{C}$ are associated with very high temperature gas reactors, molten salt reactors, and vapor core reactors. 
The phrase "here there be dragons" was written on maps to warn ancient mariners against venturing beyond the edge of the known world. The very high temperature operating environments proposed for some Generation IV reactor designs might be similarly demarcated. Most conventional metallic alloys, those for which a reasonable experimental database and broad operation experience exists, cannot be used in this temperature range where thermal creep and creep rupture are the limiting phenomena. All of the issues discussed above in the section on temperatures between 600 and $900^{\circ} \mathrm{C}$ apply here also, with the emphasis proportionally increased. Possible alternate materials may have acceptable high-temperature performance but there are insufficient data to design complex engineering structures, particularly those that will be exposed to neutron radiation.

Of the potential metal-based systems, only tungsten- and molybdenum-based systems are believed to have the potential to operate in this temperature range. Little or no data exist on the development of microstructure under irradiation for either of these systems. There is virtually nothing known about void formation, swelling, RIS, dislocation microstructure or precipitate formation and stability under irradiation at temperatures above $900^{\circ} \mathrm{C}$. Transmutation could become a more significant problem in some systems such as tungsten, where transmutation leads to the formation of rhenium that precipitates as a metallic phase. The extreme temperatures also present a problem in conducting controlled experiments in existing irradiation facilities.

Molybdenum-base and tungsten-base alloys may have sufficient creep strength at temperatures up to 1100 and $1200^{\circ} \mathrm{C}$, respectively. However, as noted in the previous section, these alloys tend to be inherently brittle and further degraded by irradiation exposure. Their sensitivity to further embrittlement is increased by exposure to oxygen. A similar problem has also been discovered for high-temperature intermetallics and monolithic ceramics. Experience from the aerospace industry indicates that the use of ceramic coatings may limit corrosion and impurity pickup, but there is no information on the stability of these coatings in an irradiation environment.

This leaves ceramic composites as possibly the best option for these very high-temperature applications. $\mathrm{SiC}-\mathrm{SiC}$ would be a first choice for temperatures up to $\sim 1000^{\circ} \mathrm{C}$ since it is the only 
composite system for which even a limited amount of irradiation effects data are available. Initial results suggest that ceramic fibers with better high-temperature strength will be required to achieve higher operating temperatures. Concerns about the effect of helium produced by nuclear transmutation in $\mathrm{SiC}$ also increase as the temperature increases. If reactor designs with component temperatures in this range are to be seriously pursued, an effort must be made to identify and investigate a range of possible candidate ceramics and ceramic composites.

For high temperature reactors, the following issues are considered the most critical:

- Understanding the complex, composition-dependent microstructural development that occurs in this temperature range.

- Development and fundamental understanding of radiation performance of refractory alloys, ceramic composites, and coatings for high temperature concepts.

\section{Welding and Joining}

The workshop did not dedicate significant time to the discussion of welding and joining, but this topic is expected to be important for both unirradiated and irradiated materials used in Generation IV systems. As an example, one class of materials being discussed to allow increased reactor operating temperatures is oxide-dispersion strengthened alloys. These materials contain large amounts of oxide particles distributed on a very fine scale, and will present a major challenge for welding. Conventional arc, laser or electron beam welding techniques would require filler metals to join ODS alloys to prevent unwanted oxide/heat-source interactions that would occur during autogeneous welding of ODS alloys. Existing filler metals may not provide the exceptional high temperature properties of these ODS materials. Research to develop high-temperature ODS filler metals, or to investigate solid state joining methods such as friction stir welding or explosive cladding where the problems associated with melting ODS alloys using conventional welding techniques can be avoided would be useful. For other new 
materials developed under Generation IV, each is expected to have its own unique set of issues related to welding and joining.

\section{Basic Science Issues}

The intent of the Workshop was to identify needs and opportunities in materials research aimed at performance improvements of structural materials in high temperature reactors. The needs and opportunities identified were to span from fundamental mechanistic understanding of materials performance to application in nuclear energy systems. The recommendations on the most important fundamental science are described in this section.

\section{Microstructural Development}

The International Conference held at Albany in June of 1971 ushered in a new era of fundamental research in radiation effects in metals and alloys. It was motivated and guided by the surprising discovery of void swelling, a phenomenon that was unexpected at the high irradiation temperatures in nuclear power reactors. Since that time, an enormous amount of excellent research has been conducted on the microscopic nature of radiation effects at elevated temperature, at which the most basic defects, vacancies and interstitials, are mobile. Although most of the defects produced in the collision cascades annihilate and restore the material to its equilibrium state, it was realized that a subtle bias exists in this complex system driven continuously from its equilibrium state which is the ultimate cause of void swelling, irradiation creep, phase stability, and the change in mechanical properties. In addition, radiation-induced segregation of impurity and alloying elements to grain boundaries, dislocations, and voids can occur, and this in turn can trigger dissolution as well as formation of new phases and precipitates. Each of these radiation effects has become a topic of in-depth research and scientific inquiry, and each displays a richness of diverse behavior, depending on the material, the irradiation temperature, the dose, and even the dose rate. 
Yet in spite of this bewildering complexity, there have also emerged similarities and universal features. For instance, all metals and alloys studied so far have exhibited void swelling when subjected to irradiation in the temperature range between about 0.3 to 0.65 of their respective melting points. Void swelling is preceded by an incubation period which can last from only 0.1 dpa to $100 \mathrm{dpa}$, followed by a steady-state swelling stage which may or may not merge into a saturation stage. In parallel with the incubation, dislocation loops form and grow, eventually merging with the network dislocations. The latter continues to evolve until a saturation density is reached which, at least in austenitic steels, has been found to be independent of the initial dislocation density.

Another phenomenon, namely irradiation-enhanced creep appears to be a universal radiation effect at temperatures below 0.65 of the melting point. In fact, it probably occurs at all temperature, but it becomes masked by thermal creep at higher temperatures.

Irradiation creep commences long before the onset of void swelling, yet it becomes closely coupled to void swelling. There are indications from breeder reactor experiments that irradiation creep may disappear when void swelling reaches its steady-state rate. At that point, the radiationinduced expansion rate even under tensile loads is limited by the expansion rate of un-stressed material.

The universality of the total rate of expansion is again a surprising discovery that was not supposed to occur. It cannot be understood from present theoretical models of void swelling and irradiation creep.

It appears that after 30 years of much detailed and in-depth research, the sum of all radiation effects does not add up entirely to the full behavior of a material exposed to continuous irradiation at elevated temperatures. This, as we now know, is the hallmark of the dynamic and kinetic response of a complex system when driven far from thermodynamic equilibrium. The 
detailed kinetic processes are both deterministic and stochastic, they are coupled, and may evolve into new kinetic processes as the microstucture of the system evolves.

The crucial components or elements of the microstructure that evolve with irradiation are voids and bubbles, dislocation loops and stacking fault tetrahedra, and network dislocations. In addition, in many types of steels, carbides and other precipitates may form during the incubation period for void nucleation and influence the evolution of the other three microstructural elements. Finally, the generation of nuclear reaction products introduces potent elements for assisting void nucleation and growth. In particular, the diffusion and segregation of helium and hydrogen to vacancy clusters and voids is a major ingredient in modeling void swelling.

The major scientific challenge in the field of radiation effects in solids is the co-evolution of all these components of the microstructure, and their roles in the macroscopic response in terms of swelling, anisotropic growth, irradiation creep, and radiation-induced phase transformations. The framework for this new era of radiation effects research should be the science of complex systems. While this emerging field is still in its definition phase, the new topic proposed for radiation effects in solids is well defined. It may in fact serve as a prime example or model of a complex system evolving in response to the continuous flow of energy which maintains the system in various states of non-equilibrium.

The fundamental basis for developing radiation-resistant materials for high-temperature reactor concepts must be established. For example in strengthened metallic alloys, critical understanding of the radiation stability of all phases is essential, taking into account the complex interactions taking place in the evolving system on the nanoscale. This requires mechanistic modeling of radiation damage processes in a wide range of metallic, intermetallic and ceramic phases plus the ability to model collective damage evolution in an integrated system. While a strong underpinning capability exists for many simple metals, the ability to assess behavior in complex alloys or in non-metallic systems is very limited. 


\section{Deformation \& Embrittlement}

Displacement damage during irradiation creates a non-equilibrium, structure-chemistry evolution at the nanoscale and alters plasticity, corrosion-oxidation and fracture processes. Fundamental understanding of these complex, interdependent, radiation-induced material changes is essential to underpin the development of Generation IV reactor systems. Remarkable advances over the last 20 years in measurement and modeling tools (driven in most cases by the Office of Basic Energy Sciences) enables a unique opportunity to establish the critical foundation for radiationresistant materials development. Atomistic response defining structural behavior of irradiated materials can be interrogated for the first time.

Deformation and embrittlement issues at various temperature regimes critical to Generation IV reactor concepts were evaluated. In each temperature range, options for core structural materials were identified along with important performance limitations, materials development needs and core underpinning science issues.

Radiation-induced evolution of non-equilibrium structures and chemistries alter the basic deformation processes within the matrix and grain boundaries. Complex interactions among defects (clusters, loops, bubbles and voids), including elemental segregation, precipitation and dynamic dislocation processes are poorly understood. Key research has been initiated in isolated simple systems, but must be expanded to address fundamental issues controlling defect-defect interactions, flow localization through segregated defect nanostructures and interfacial deformation (dislocation emission, transmission and sliding).

The key structural performance issues for most irradiated metallic alloys are time-independent embrittlement at low temperatures and time-dependent cracking at high temperatures. The evolution of non-equilibrium structures and chemistries promote a hardened matrix and lower grain boundary cohesive strengths thereby reducing the tensile stress required for cleavage or intergranular fracture. At high temperatures, the radiation-induced changes in the matrix and particularly at grain boundaries can promote creep embrittlement. Irradiation provides a 
challenge and an opportunity to explore the basic processes controlling transgranular and intergranular processes. The competition between matrix and grain boundary processes is an integral part of deformation and fracture in both irradiated and unirradiated materials. Advances in modeling and measuring the atomistics of fracture need to be combined with micromechanical models to better elucidate behavior in complex radiation-induced, multi-component nanostructures.

Although corrosion issues were not directly assessed within the Workshop, environment-assisted cracking was identified as a primary materials issue for most reactor concepts. Underpinning research focused on the unique radiation-environment interactions that promote irradiationassisted stress corrosion cracking and dynamic embrittlement is needed. Fundamental unknowns were recognized for radiation-enhanced corrosion and cracking in supercritical water and lead-based coolants.

\section{High temperature, time dependent deformation and fatigue}

Investigation of non-equilibrium thermodynamics in driven systems and on the nanoscale is needed. Understanding this behavior has direct implications to the performance of several materials that may be used in Generation-IV reactors.

The presence of persistent point defect supersaturations in materials undergoing displacive irradiation give rise to unique phenomena, such as radiation-induced solute segregation and solute clustering. This environment provides a unique opportunity to study material behavior far from equilibrium.

The formation and evolution of nanoscale solute-oxide clusters in metals and alloys during mechanical alloying and subsequent thermo-mechanical treatment. These clusters appear to demonstrate non-equilibrium thermodynamic behavior, e.g. in their composition and diffuse interfaces. 
Mechanisms influencing dislocation motion and plasticity in materials containing a finelydispersed nanoscale second phase are not well understood. Cottrell-like atmospheres consisting of the same solutes that are contained in the nanophases have been observed. The relative importance of these atmospheres and the nanophases in strengthening these materials is not known.

Time-dependent, high-temperature plasticity associated with crack growth when both thermal creep and fatigue mechanisms are operative is not well understood. The effect of creep-fatigue interaction on the local microstructure in front of the crack tip, and the feedback due to microstructural changes may influence subsequent crack growth.

\section{Cross Cutting R\&D}

Many materials R\&D areas were identified to support development of Generation IV concepts. Table 5 lists the different concepts proposed for Generation IV and the expected degradation issues. In any situation with limited budgets, choices must be made regarding the research that is most effective at advancing the concepts. This research could be crosscutting and therefore applicable to many concepts or critical to the advancement of a specific concept. Based on the discussions at this workshop, the following areas appear to be the most critical for advancing Generation IV concepts.

- Research on advanced ferritic-martensitic and martensitic steels that allow for increased temperature of operation for liquid-metal and supercritical water concepts and improving toughness at lower temperatures. Issues include stability of oxides in ODS materials, basic microstructural and microchemical changes, and phase stability at high temperatures.

- Development and fundamental understanding of radiation performance of refractory alloys, ceramic composites, and coatings for high and very high temperature concepts. 
- Research to improve radiation performance of austenitic stainless alloys including resistance to void swelling, embrittlement and stress corrosion cracking.

- Development of new high-temperature superalloys that are tailored for radiation environments (e.g., low nickel contents and controlled phase stability)

- Fundamental and applied understanding of the complexity of radiation damage in engineering alloys, including austenitic, ferritic, ferritic-martensitic, refractory, and ceramic materials.

- Fundamental and applied understanding of deformation and creep processes related to flow localization and grain boundaries.

- Fatigue in plants that are expected to load follow

- Developing design data for nuclear graphite

Although corrosion was not a specific consideration of this workshop, the attendees do noted that significant corrosion related challenges must be overcome before certain Generation IV concepts are viable.

- Corrosion in supercritical water

- Corrosion in lead or lead-bismuth

- Corrosion in molten salts

- Compatibility of fuels and cladding

Additionally, several fundamental science issues were identified:

- The co-evolution of all components of the microstructure, and their roles in the macroscopic response in terms of swelling, anisotropic growth, irradiation creep, and radiation-induced phase transformations should be studied within the of the science of complex systems.

- Displacement damage during irradiation creates a non-equilibrium, structure-chemistry evolution at the nanoscale and alters plasticity, corrosion-oxidation and fracture processes. Fundamental understanding of these complex, interdependent, radiation-induced material changes is essential to underpin the development of Generation IV reactor systems. 
- Key structural performance issues for most irradiated metallic alloys are time-independent embrittlement at low temperatures and time-dependent cracking at high temperatures. The evolution of non-equilibrium structures and chemistries promote a hardened matrix and lower grain boundary cohesive strengths thereby reducing the tensile stress required for cleavage or intergranular fracture. Advances in modeling and measuring the atomistics of fracture need to be combined with micromechanical models to better elucidate behavior in complex radiation-induced, multi-component nanostructures.

\section{Readiness of Research Facilities}

Proper study and evaluation of materials for Generation IV systems requires irradiation facilities and the facilities to prepare and analyze samples. Currently, the U.S. does not have a fast spectrum irradiation capability. Many Generation IV concepts that optimize recycle are based on fast spectrum systems. To irradiate materials in a fast spectrum requires the use of either the JOYO reactor in Japan, BOR-60 in Russia, or PHENIX in France. Thermal spectrum facilities exist in the U. S. at the Advanced Test Reactor at the INEEL and the High Flux Isotope Reactor at ORNL.

While neutron irradiations are essential to evaluate and qualify materials for Generation IV systems, it is important to note that effective radiation effects experiments can be performed using ion-beam facilities. Currently DOE NE is sponsoring work using ion-beam facilities at both the University of Michigan and PNNL. These facilities are good for studying microstructural and microchemical changes during irradiation as well as corrosion and mechanical properties in many circumstances. However, the higher dose rates must be taken into account and the depth of penetration is typically not sufficient to assess bulk mechanical properties. Charged particle irradiations can provide a low-cost method for conducting valuable radiation effects research in the absence of, or as a precursor to verification experiments in reactors. Some specialized facilities such as the ORNL triple beam facility and the ANL $1 \mathrm{MeV}$ electron microscope have been closed in recent years. As a result, existing facilities, while of 
high quality, are inadequate to handle the entire workscope required for a major alloy design and verification effort.

Dedicated hot-cell facilities are required to examine radioactive materials. Due to lack of support, many hot-cell facilities are being decommissioned. While not severely limiting materials R\&D yet, without adequate programmatic support, more important hot-cell capacity may be lost in the near future. In addition to maintaining existing capabilities, it is important to note that most hot-cell facilities are more than 30 years old. Modern facilities for the handling and testing of radioactive materials are needed. A vital capability in this regard has been the development of small-specimen testing methods capable of generating high-quality data for bulk properties.

\section{Readiness of Research Personnel}

An increase in research on materials for advanced reactor concepts will require not only financial resources, but the human resources to carry out the plan. The latter may in fact become limiting in light of the shrinkage and aging of the workforce in the nuclear field over the past two decades. In the national laboratory community, only three labs (ORNL, ANL and PNNL) have a critical mass of scientists that can contribute in a significant way to research in materials for advanced reactor concepts. In academia, there are only about 15 faculty currently active in nuclear materials research in the nation's nuclear engineering departments, where most of this type of research is conducted. In industry, there are only a few companies with laboratory capabilities and manpower capable of conducting research on materials for advanced reactor concepts. If the goal is to develop a knowledge base of materials issues on more than once advanced reactor concept, the human resources in the US will be extremely strained. 


\section{Academia}

In January of 2000, the Nuclear Engineering Department Heads Organization (NEDHO), published a report entitled "Manpower Supply and Demand in the Nuclear Industry" that contained a survey and assessment of manpower in the nuclear industry [5]. The Manpower Survey resulted in a quantitative assessment of both the supply and the demand for nuclear engineers out to the year 2003. The results show that the demand - supply gap increases monotonically from 1999 to 2003. The results of the survey are summarized below:

For the supply side:

- 29 nuclear engineering departments continue to award either the B.S. or the M.S. in nuclear engineering or both,

- Nuclear engineering departments report a relatively stable supply of NE graduates through the year 2000-2001,

- Nuclear engineering departments will collectively graduate an average of 110 B.S. students per year that have focused their studies in fission engineering, of which about 83 are expected to be available for employment in the nuclear industry,

- Nuclear engineering departments will graduate an average of $106 \mathrm{M}$. S. students per year that have focused their studies in fission engineering, of which about 80 are expected to be available for employment in the nuclear industry.

For the demand side, the survey results are summarized as follows:

- $52 \%$ of organizations contacted responded to the survey,

- $91 \%$ of respondents expect to hire nuclear engineers within the next 5 years,

- $78 \%$ of organizations will hire fresh graduates,

- $74 \%$ will hire non-nuclear engineers with nuclear engineering knowledge,

- $61 \%$ are having difficulty recruiting nuclear engineers, 
- The average yearly demand of $52 \%$ of the organizations contacted is 337 engineers with either a B.S. or a M.S. degree,

- Of 497 vacancies in 1998, 316 were filled by nuclear engineers.

The survey primarily assessed the production of and demand for BS and MS graduates in the fission reactor area. Much of the research on materials for advanced reactors will be conducted by $\mathrm{PhDs}$ in academia, national laboratories and nuclear-oriented companies, and needs to be included in any assessment of available human resources. To this end, the enrollment and degree production of all levels of nuclear engineers is shown in Figure 5. As noted, there has been a startling decrease in BS enrollment starting in the early 90s and leveling off at the end of the decade. The decrease is tempered somewhat at the MS level and more so at the PhD level. Nevertheless, the total amount of graduates represents a fairly low production rate that is insufficient to maintain the current level of research activity across the various organizations, let alone accommodate an expansion of research.

Not all of the manpower for advanced reactor materials will come from the nuclear engineering discipline. Yet there are similar concerns regarding the availability of talent to address an increase in research. Figure 6 shows undergraduate degree production and graduate enrollment in several fields including life sciences, physical sciences and engineering in the U.S. over the past 10-15 years. Over this time period, there has been tremendous growth in the graduate student population in the life/biological sciences and a decline in population of engineering and the physical sciences. Figure 7 shows that the graduate program enrollment in science and engineering is further challenged by a declining domestic student population, and increasingly buttressed by foreign graduate students. Since Generation IV Systems critically rely on advances in materials, energizing an interest among material science departments is an important step.

\section{Industry}

In 2001, the Nuclear Energy Institute (NEI) completed an extensive survey focused on the staffing and recruiting projections from 2002 to 2011, called the Nuclear Industry Staffing 
Pipeline Survey [6]. In consultation with a diverse group of individuals representing various sectors, they identified actions underway or planned that support building a reliable workforce pool of entry-level workers for the industry over the next decade and beyond. This document was intended to be fluid and flexible - allowing growth in concepts and programs as more is known and progress occurs. Key conclusions from the survey included:

- The industry's demand for new staff will increase dramatically over the next 10 years. Approximately 90,000 entry-level workers are estimated to be needed to fill vacancies in thirteen job classifications simply to support the existing operations. Demand for graduates in nuclear engineering will be 50-100\% greater than the supply.

- The demand for degreed health physicists and nuclear engineers, although small by comparison in numbers, will significantly outstrip the supply for the next decade. A particular difficulty in employing degreed health physicists is that the demand for these candidates extends well beyond the nuclear energy industry. The shortage in nuclear engineers is expected to equal about 800 over the next 10 years.

- While the availability of other degreed professionals, operators and skilled craft is adequate, stiff competition with other industries is expected. And, the experience and incoming qualifications of these entry-level workers are likely to be less.

- The nuclear energy industry is in a good position to compete for qualified employees in the current and future job markets. The industry is competitive in terms of overall employee compensation and in the six benefit categories that were examined in the study.

\section{National Laboratories}

Detailed reports for national laboratory manpower were not located in the process of writing this report. A recent report for DOE from the Laboratory Directors [7] did note that, even after accounting for differences in degree levels, the DOE Labs have a significantly smaller proportion of scientists and engineers under the age of forty than the US norm ( $26 \%$ vs $40 \%)$. Additionally, the national laboratories had very high attrition rates (greater than 8\%) for scientists 34 years old and 
younger. Anecdotal evidence indicates that DOE laboratories will have staffing shortages similar to academia and industry in meeting the demands of a significant growth in R\&D to support Generation IV.

\section{Reactor Materials Areas not Specifically Addressed}

To control the workshop scope to a manageable level, the workshop did not address all of the issues that significantly weigh on the choice of materials for Generation IV systems.

Specifically, the following items relative to structural materials were not addressed:

- Chemical compatibility and corrosion issues

- Material availability, cost, fabricability, joining technology

- Safety and waste disposal aspects (decay heat, etc.)

- Nuclear properties (neutron economy, solute burnup, etc.)

All of these issues play a critical role in determining if reactor concepts can be operated safely and reliably and at a reasonable cost. Because many of the proposed Generation IV concepts operate in unique coolants (e.g. lead, lead-bismuth, supercritical water, molten salt), research and development will be required to establish materials that can operate in these environments. Material availability and cost is certainly an issue. Table 6 demonstrates the varied costs associated with possible Generation IV materials.

Another major technology area not discussed was reactor fuels and fuel-cladding compatibility. Fuels are critical to Generation IV concepts, especially considering that sustainability is considered an important Generation IV goal. Fuels that are compatible with recycle systems and stable waste forms must be developed. 
Materials issues in recycle systems were recognized as important, but were not discussed in depth at this workshop. To be economically viable, recycle systems must minimize process losses. Materials improvements in all steps of the recycle process are needed.

\section{Recommendations for Future Workshops}

This workshop proved to be a useful first discussion about the materials aspects of Generation IV nuclear energy systems. Because Generation IV reactor systems were not well enough defined at the time of the workshop to identify specific operating environment, the workshop took a rather broad view of materials issues. At the completion of the Generation IV Roadmap, the number of concepts being considered will be fewer than those considered at this workshop. Future workshops should aim to discuss a narrower issue in greater technical depth.

The workshop participants noted that in the area of reactor structural materials for Generation IV systems, many of the alloy systems to be considered are also being considered in the fusion reactor development community. Coordination of future workshops and R\&D plans with the fusion reactor community would prove useful and optimize R\&D resources.

Possible topics for future workshops include:

- Coolant specific corrosion and environmental cracking issues relative to specific Generation IV concepts (e.g., in lead-base, molten-salt, or supercritical water coolants)

- Materials to minimize process loss in fuel recycle systems

- Fuel development for specific Generation IV systems (e.g., nitride fuel development)

Because R\&D on specific Generation IV concepts will start in the fall of 2002 at the earliest, a workshop in the Summer/Fall of 2003 is likely to be properly timed to ensure significant issues and results can be discussed. 


\section{References}

1. S. J. Zinkle, private communication

2. S. J. Zinkle and N. M. Ghoniem, "Operating temperature windows for fusion reactor structural materials", Fusion Eng. Design 49-50, 709 (2000).

3. S. J. Zinkle, L. J. Ott, D. T. Ingersoll, R. J. Ellis, and M. L. Grossbeck, "Overview of materials technologies for space nuclear power and propulsion, in Proceedings of the Space Technology and Applications International Forum-2002" (STAIF-2002), edited by M. S. ElGenk (American Institute of Physics, 2002), p. 1063.

4. F. A. Garner, "Irradiation Performance of Cladding and Structural Steels in Liquid Metal Reactors", in Materials Science and Technology, A Comprehensive Treatment, Vol $10 \mathrm{~A}$ Nuclear Materials, Eds., R. W. Cahn, P. Haasen, and E. J. Kramer, (VCH Weinheim, 1994).

5. G. S. Was and W. R. Martin, "Manpower Supply and Demand in the Nuclear Industry", eds., Nuclear Engineering Department Heads Organization, January, 2000.

6. "Integrated Plan for Nuclear Industry Staffing Pipeline", Nuclear Energy Institute, March, 2002.

7. Joan Woodard, Deputy Director of Sandia National Laboratories, DOE Workforce Issue Paper, "Report of the Taskforce on Workforce Challenges for the DOE Laboratories", December 2000.

8. "Nuclear Engineering Enrollment and Degrees Brief", Oak Ridge Institute for Science and Education Managed for DOE by ORAU, Number 50, April, 2002. 
Table 1. Principal Primary Operating Temperature Ranges for Generation IV Reactor Concepts

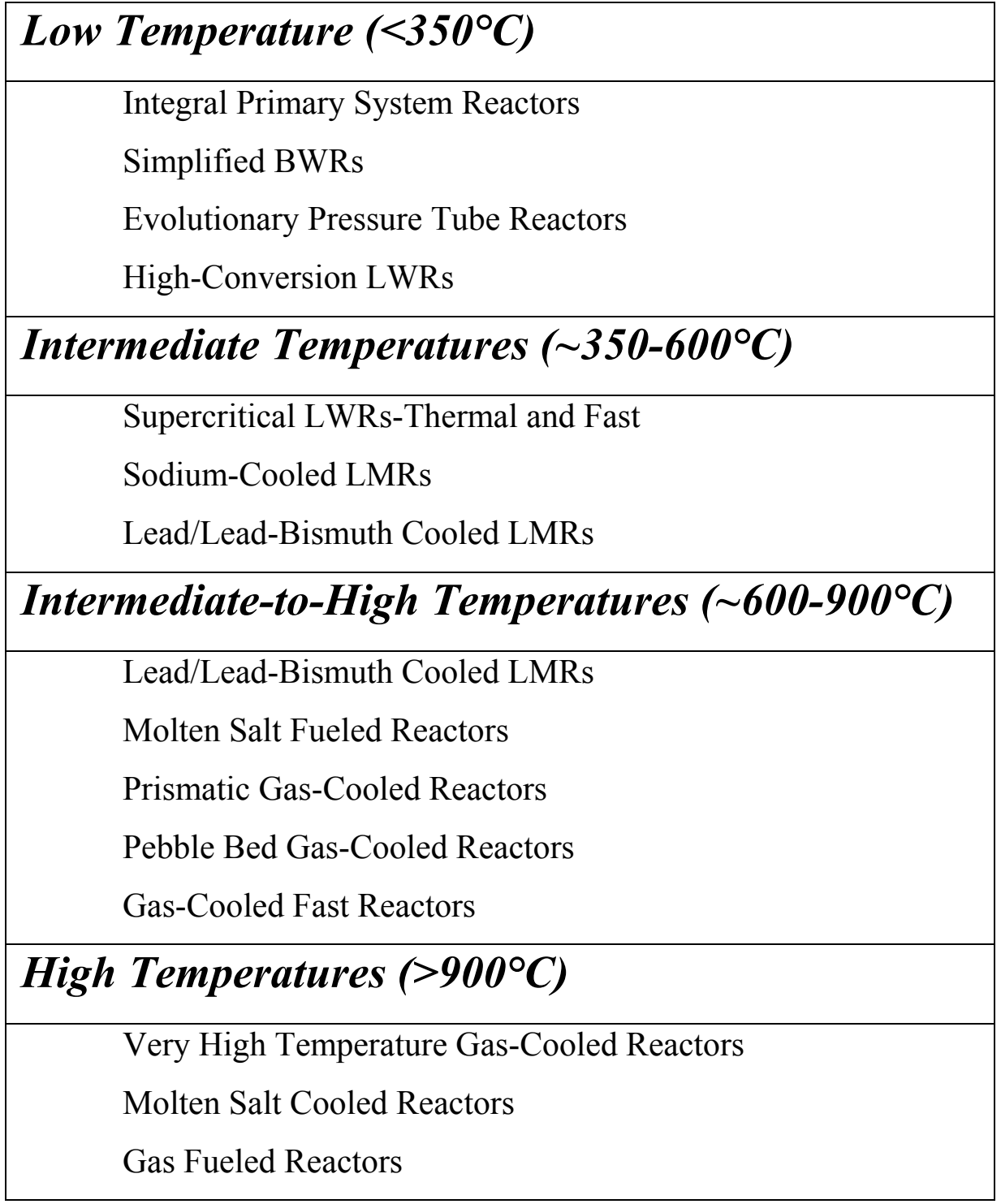


Table 2. List of candidate materials and performance issues for low temperature $\left(<\sim 350^{\circ} \mathrm{C}\right)$ applications

\begin{tabular}{|l|l|}
\hline \multicolumn{1}{|c|}{ Structural Material } & \multicolumn{1}{c|}{ Performance Issues } \\
\hline $\begin{array}{l}\text { Ferritic Pressure } \\
\text { Vessel Steels }\end{array}$ & Radiation Embrittlement (Toughness, DBTT) \\
\hline $\begin{array}{l}\text { Fe-Base Austenitic } \\
\text { Stainless Steels }\end{array}$ & SCC, IASCC, High-Dose Embrittlement \\
\hline $\begin{array}{l}\text { Ni-Base Stainless } \\
\text { Alloys \& Superalloys }\end{array}$ & IGSCC, IG Corrosion, Weld Metal SCC, IASCC \\
\hline Zirconium Alloys & Corrosion, Hydriding \\
\hline $\begin{array}{l}\text { Ferritic/Martensitic } \\
\text { Alloys e }\end{array}$ & \begin{tabular}{l} 
Radiation Embrittlement (Toughness, DBTT), IGSCC, IASCC, \\
\hline
\end{tabular} \\
\hline
\end{tabular}

Table 3. List of candidate alloys and performance issues for intermediate temperature $\left(\sim 350-650^{\circ} \mathrm{C}\right)$ applications

\begin{tabular}{|l|l|}
\hline \multicolumn{1}{|c|}{ Structural Material } & \multicolumn{1}{c|}{ Performance Issues } \\
\hline Pressure vessel steels & Radiation embrittlement, (toughness, DBTT) \\
\hline Fe-base austenitic stainless steels & $\begin{array}{l}\text { Creep strength, swelling \&embrittlement, corrosion, } \\
\text { IASCC }\end{array}$ \\
\hline Ni-base austenitic alloys and superalloys & $\begin{array}{l}\text { He embrittlement, creep strength, swelling \& } \\
\text { embrittlement, corrosion, IGSCC, IASCC }\end{array}$ \\
\hline Ferritic-Martensitic alloys & $\begin{array}{l}\text { Radiation embrittlement (toughness, DBTT), } \\
\text { corrosion, IASCC, hydrogen cracking, corrosion in } \\
\text { led-based coolants and molten salts }\end{array}$ \\
\hline
\end{tabular}

Table 4. List of candidate materials and performance issues for high temperature applications

\begin{tabular}{|l|l|}
\hline \multicolumn{1}{|c|}{ Structural Material } \\
$\begin{array}{l}\text { Iron and nickel-based } \\
\text { superalloys }\end{array}$ & Creep behavior, Toughness, He Embrittlement \\
\hline $\begin{array}{l}\text { Ferritic-martensitic } \\
\text { alloys }\end{array}$ & $\begin{array}{l}\text { Creep behavior, Toughness, Radiation-induced embrittlement, } \\
\text { Corrosion in lead-based coolants and molten salts, dispersion stability } \\
\text { in ODS alloys }\end{array}$ \\
\hline $\begin{array}{l}\text { Refractory metal } \\
\text { alloys }\end{array}$ & $\begin{array}{l}\text { Creep behavior, Toughness, Radiation-induced embrittlement, } \\
\text { Corrosion, Oxidation, Impurity pickup }\end{array}$ \\
\hline $\begin{array}{l}\text { Ceramic composites } \\
\text { \& coatings }\end{array}$ & $\begin{array}{l}\text { Creep behavior, Radiation and environmental effects on interfaces, } \\
\text { Toughness, Corrosion in lead-based coolants or molten salts }\end{array}$ \\
\hline Graphite & Creep strength, Swelling, Toughness, Thermal conductivity \\
\hline
\end{tabular}


Table 5. Principal Primary Loop Structural Materials Issues for Generations IV Reactor Concepts

\begin{tabular}{|c|c|c|c|}
\hline Concept Group & $\begin{array}{c}\text { Coolant } \\
\text { Temps }\left({ }^{\circ} \mathrm{C}\right)\end{array}$ & $\begin{array}{l}\text { Principal Structural Materials Identified } \\
\text { Other Structural Materials Probable }\end{array}$ & $\begin{array}{l}\text { Principal Materials Issues Identified } \\
\text { Other Key Issues? }\end{array}$ \\
\hline Simplified BWRs & $215-300$ & $\begin{array}{l}\text { Zr Alloy Cladding } \\
\text { Ni-Base Alloy Steam Generator Tubes } \\
\text { Ferritic Steel Vessel } \\
\text { Austenitic Stainless Steel Core Internals } \\
\end{array}$ & $\begin{array}{l}\text { Time-dependent behavior at high burnup } \\
\text { Zircaloy corrosion/hydriding at high burnup } \\
\text { Fuel-side corrosion by (U,Th) O2 fuels } \\
\text { IASCC, HIC, Prim/Sec. IGSCC, Vessel DBTT }\end{array}$ \\
\hline $\begin{array}{l}\text { Evolutionary Pressure } \\
\text { Tube Reactors }\end{array}$ & $310-330$ & $\begin{array}{l}\text { Zr and Zr-Nb Alloy Cladding/Pressure Tube } \\
\text { Ferritic Steel Vessel } \\
\text { Stainless Steel (Unspecified) Pressure Tube }\end{array}$ & $\begin{array}{l}\text { Fuel-side corrosion by (U,Th)O2 fuels } \\
\text { Zircaloy corrosion/hydriding } \\
\text { Internals Swelling, IASCC, Primary/Sec. IGSCC }\end{array}$ \\
\hline $\begin{array}{l}\text { Integral Primary } \\
\text { System LWRs }\end{array}$ & $270-330$ & $\begin{array}{l}\text { Zr Alloy Cladding } \\
\text { Ni-Base Alloy SG Tubes } \\
\text { Ti-Base Alloy SG Tubes } \\
\text { Ferritic Steel Vessel } \\
\text { Austenitic Stainless Steel Core Internals }\end{array}$ & $\begin{array}{l}\text { Time-dependent behavior at high burnup } \\
\text { Zircaloy corrosion/hydriding at high burnup } \\
\text { Fuel-side corrosion by burnable poisons } \\
\text { Corrosion/erosion of Ti-alloy SG tubes } \\
\text { Corrosion of in-vessel components } \\
\text { Swelling, IASCC, IGSCC, Vessel DBTT }\end{array}$ \\
\hline Pebble-Fueled PWR & $300-350$ & $\begin{array}{l}\mathrm{UO} 2+\mathrm{Zr} \text { Alloy Clad Fuel } \\
\text { Structural Alloys (Unspecified) } \\
\text { Austenitic SS Core Internals }+ \text { Ferritic Steel PPV }\end{array}$ & $\begin{array}{l}\text { Fabrication of } \mathrm{Zr} \text { coatings on } \mathrm{UO} 2 \text { spheres } \\
\text { Erosion/fretting of } \mathrm{Zr} \text { coatings, corrosion/hydriding } \\
\text { Internals Swelling, IASCC, Primary/Sec. IGSCC }\end{array}$ \\
\hline Pebble-Fueled BWR & $285-370$ & $\begin{array}{l}\text { Layered Particulate Fuel } \\
\text { Structural Alloys (Unspecified) } \\
\text { Ferritic Steel Vessel } \\
\text { Austenitic Stainless Steel Core Internals }\end{array}$ & $\begin{array}{l}\text { Wear of components by } \mathrm{SiC} \text {, Erosion/corrosion of } \mathrm{SiC} \\
\text { Diffusion of fission products through } \mathrm{SiC} \\
\text { Stability of fuel layers at high burnup } \\
\text { Swelling, IASCC, IGSCC }\end{array}$ \\
\hline $\begin{array}{l}\text { High-Conversion } \\
\text { LWRs }\end{array}$ & $\begin{array}{c}\text { Unspecified } \\
(<350 ?)\end{array}$ & $\begin{array}{l}\text { Zircaloy Cladding } \\
\text { Structural Alloys (Unspecified) } \\
\text { Austenitic SS Internals, Ferritic Steel RPV }\end{array}$ & $\begin{array}{l}\text { Irradiation behavior of } \mathrm{Zr} \text { in hardened spectrum } \\
\text { Fuel-side corrosion by }(\mathrm{U}, \mathrm{Th}) \mathrm{O} 2 \text { fuels }\end{array}$ \\
\hline $\begin{array}{l}\text { Passive Pressure } \\
\text { Tube Reactor }\end{array}$ & $\begin{array}{c}\text { Unspecified } \\
(<350 ?)\end{array}$ & $\begin{array}{l}\text { TRISO Fuel } \\
\text { SiC Coatings on Moderator/Fuel Matrix } \\
\text { Graphite Moderator/Fuel Matrix } \\
\text { Zr Alloy Pressure Tube } \\
\text { Ferritic Steel Vessel }\end{array}$ & $\begin{array}{l}\text { Fabrication/inspection of TRISO fuel } \\
\text { Diffusion of fission products through } \mathrm{SiC} \\
\text { Fabrication of structural } \mathrm{SiC} \text { composites } \\
\text { Time-dependent behavior of } \mathrm{SiC} \text { coatings/composites } \\
\text { Corrosion of } \mathrm{SiC} \text { or } \mathrm{SiC} / \mathrm{SiC} \text { cladding in water }\end{array}$ \\
\hline
\end{tabular}


Table 5. (continued) Principal Primary Loop Structural Materials Issues for Generation IV Reactor Concepts

Intermediate Temperatures ( 350-600 ${ }^{\circ} \mathrm{C}$, Evolutionary from LWR/Fossil, FBR + Some Unknowns)

\begin{tabular}{|c|c|c|c|}
\hline Concept Group & $\begin{array}{c}\text { Coolant } \\
\text { Temps }\left({ }^{\circ} \mathrm{C}\right)\end{array}$ & $\begin{array}{l}\text { Principal Structural Materials Identified } \\
\text { Other Structural Materials Probable }\end{array}$ & $\begin{array}{l}\text { Principal Materials Issues Identified } \\
\text { Other Key Issues? }\end{array}$ \\
\hline $\begin{array}{l}\text { Supercritical Thermal } \\
\text { LWRs }\end{array}$ & $375-500$ & $\begin{array}{l}\text { Ni-Base Alloy Cladding } \\
\text { Ferritic RPV } \\
\text { Ferritic SS Core Internals? } \\
\text { Different Cladding }\end{array}$ & $\begin{array}{l}\text { Swelling, He, Creep of Ni-base alloy cladding } \\
\text { Swelling \& Embrittlement of core internals } \\
\text { Corrosion/SCC/IASCC in supercritical water }\end{array}$ \\
\hline $\begin{array}{l}\text { Pebble-Fueled } \\
\text { Supercritical LWR }\end{array}$ & $280-540$ & $\begin{array}{l}\text { TRISO Fuel } \\
\text { Structural Alloys (Unspecified) } \\
\text { Ferritic RPV } \\
\text { Ferritic SS Core Internals? }\end{array}$ & $\begin{array}{l}\text { Corrosion of } \mathrm{SiC} \text { in boiling water } \\
\text { Diffusion of fission products through } \mathrm{SiC} \\
\text { Erosion of } \mathrm{SiC} \text {, wear of other alloys by } \mathrm{SiC} \\
\text { Corrosion/SCC/IASCC in supercritical water }\end{array}$ \\
\hline $\begin{array}{l}\text { Supercritical Thermal } \\
\text { HWRs }\end{array}$ & $350-625$ & $\begin{array}{l}\text { Zr Alloy Cladding } \\
\text { Ni-Base Alloy Cladding for High Temperature } \\
\text { Ferritic SS Core Internals? }\end{array}$ & $\begin{array}{l}\text { Swelling, He, Creep of Ni-base alloy cladding } \\
\text { Swelling \& Embrittlement of core internals } \\
\text { Corrosion/SCC/IASCC in supercritical water }\end{array}$ \\
\hline $\begin{array}{l}\text { Supercritical Fast } \\
\text { LWRs }\end{array}$ & Unspecified & $\begin{array}{l}\text { ZrH1.7 Moderator (is it really fast?) } \\
\text { Stainless Steel (Unspecified) Structures } \\
\text { Ferritic RPV } \\
\text { Ferritic SS Core Internals? }\end{array}$ & $\begin{array}{l}\text { Thermal \& dimensional stability of } \mathrm{ZrH} 1.7 \\
\text { Barrier coatings to prevent } \mathrm{H} \text { loss } \\
\text { Swelling, Creep \& Embrittlement of core internals } \\
\text { Corrosion/SCC/IASCC in supercritical water }\end{array}$ \\
\hline $\begin{array}{l}\text { Sodium-Cooled } \\
\text { LMRs }\end{array}$ & $400-550$ & $\begin{array}{l}\text { Many steels identified for components } \\
\text { Ferritic High Cr and Ferritic/Martensitic Steels } \\
\text { Austenitic Stainless Steels } \\
\text { ODS Steels }\end{array}$ & $\begin{array}{l}\text { Swelling, Creep \& Embrittlement of core internals } \\
\text { Thermal or Radiation-Induced Toughness/DBTT } \\
\text { Corrosion/cracking at higher temperatures }\end{array}$ \\
\hline
\end{tabular}


Table 5. (continued) Principal Primary Loop Structural Materials Issues for Generation IV Reactor Concepts

Intermediate-to-High Temperatures ( $600-900^{\circ} \mathrm{C}$, Evolutionary + Many Critical Unknowns)

\begin{tabular}{|l|c|l|l|}
\hline Concept Group & $\begin{array}{c}\text { Coolant } \\
\text { Temps }\left({ }^{\circ} \mathbf{C}\right)\end{array}$ & $\begin{array}{l}\text { Principal Structural Materials Identified } \\
\text { Other Structural Materials Probable }\end{array}$ & $\begin{array}{l}\text { Principal Materials Issues Identified } \\
\text { Other Key Issues? }\end{array}$ \\
\hline $\begin{array}{l}\text { Lead/Lead-Bismuth } \\
\text { Cooled LMRs }\end{array}$ & $400-700$ & $\begin{array}{l}\text { Austenitic Steel } \\
\text { High Cr Ferritic Steels } \\
\text { Ferritic/Martensitic Steels } \\
\text { ODS Steels } \\
\text { Advanced High Temp Alloys }\end{array}$ & $\begin{array}{l}\text { Creep, Swelling \& Embrittlement of core internals } \\
\text { Thermal or Radiation-Induced Toughness/DBTT } \\
\text { Corrosion \& environmental cracking, IASCC }\end{array}$ \\
\hline $\begin{array}{l}\text { Molten Salt } \\
\text { Fueled Reactors }\end{array}$ & \multirow{2}{*}{$\begin{array}{l}\text { Graphite Structure } \\
\text { Ni-Base Alloy \& Ni-Mo Structures } \\
\text { Advanced High Temp Alloys }\end{array}$} & $\begin{array}{l}\text { Corrosion, environmental crackings in fluoride salts } \\
\text { Swelling, Creep \& He Embrittlement of Ni alloys } \\
\text { Thermal or Radiation-Induced Toughness/DBTT }\end{array}$ \\
\hline Prismatic Gas-Cooled & $500-850$ & $\begin{array}{l}\text { TRISO Fuel } \\
\text { Graphite Moderator } \\
\text { High Cr and Martensitic Steel Structures } \\
\text { Advanced High Temp Alloys }\end{array}$ & $\begin{array}{l}\text { Mechanical behavior of SiC at high burnup } \\
\text { Diffusion of fission products through SiC } \\
\text { Creep, Swelling \& Embrittlement of core internals } \\
\text { Thermal or Radiation-Induced Toughness/DBTT }\end{array}$ \\
\hline Pebble Bed Gas-Cooled & $500-900$ & $\begin{array}{l}\text { TRISO Fuel } \\
\text { Graphite Moderator } \\
\text { High Cr and Martensitic Steel Structures } \\
\text { Advanced High Temp Alloys }\end{array}$ & $\begin{array}{l}\text { Mechanical behavior of SiC at high burnup } \\
\text { Diffusion of fission products through SiC } \\
\text { Creep, Swelling \& Embrittlement of core internals } \\
\text { Thermal or Radiation-Induced Toughness/DBTT }\end{array}$ \\
\hline $\begin{array}{l}\text { Gas-Cooled Fast } \\
\text { Reactors }\end{array}$ & $500-900$ & $\begin{array}{l}\text { TRISO Fuel } \\
\text { Fuel Matrix (Unspecified) } \\
\text { Structural Steel (Unspecified) } \\
\text { Advanced High Temp Alloys }\end{array}$ & $\begin{array}{l}\text { Identify fuel matrix material, behavior in fast spectrum } \\
\text { Diffusion of fission products through SiC } \\
\text { Creep, Swelling \& Embrittlement of core internals } \\
\text { Thermal or Radiation-Induced Toughness/DBTT }\end{array}$ \\
\hline
\end{tabular}


Table 5. (continued) Principal Primary Loop Structural Materials Issues for Generation IV Reactor Concepts

High Temperatures $\left(>900^{\circ} \mathrm{C}\right.$, Essentially No Experience, Many Critical Unknowns)

\begin{tabular}{|c|c|c|c|}
\hline Concept Group & $\begin{array}{c}\text { Coolant } \\
\text { Temps }\left({ }^{\circ} \mathrm{C}\right) \\
\end{array}$ & $\begin{array}{l}\text { Principal Structural Materials Identified } \\
\text { Other Structural Materials Probable }\end{array}$ & $\begin{array}{l}\text { Principal Materials Issues Identified } \\
\text { Other Key Issues? }\end{array}$ \\
\hline $\begin{array}{l}\text { High Temperature } \\
\text { Gas-Cooled Reactors }\end{array}$ & $900-1250$ & $\begin{array}{l}\text { Modified TRISO Fuel (ZrC) } \\
\text { Ceramic Composite Structures } \\
\text { Refractory, Intermetallic Alloy Structures } \\
\text { Advanced High Temp Alloys } \\
\text { High-Temperature Coatings }\end{array}$ & $\begin{array}{l}\text { Thermal and dimensional stability } \\
\text { Fabrication/reliability of ceramic composites } \\
\text { Irradiation/ Mechanical behavior of } \mathrm{ZrC} \\
\text { Irradiation, creep, embrittlement for HT alloys }\end{array}$ \\
\hline $\begin{array}{l}\text { Molten Salt } \\
\text { Cooled Reactors }\end{array}$ & $1200-1600$ & $\begin{array}{l}\text { TRISO Fuel } \\
\text { Graphite Structures } \\
\text { Advanced High Temp Alloys } \\
\text { Ceramic Composites, High-Temp Coatings }\end{array}$ & $\begin{array}{l}\text { Behavior of TRISO fuel at high temperature } \\
\text { Environmental effects in flouride salts } \\
\text { Irradiation, creep, embrittlement for HT alloys } \\
\text { Irradiation, reliability of ceramic composites }\end{array}$ \\
\hline Gas Fueled Reactors & $1500-2200$ & $\begin{array}{l}\text { Refractory Carbide Fuel } \\
\text { Matrix/Structure/Vessel } \\
\text { Be/BeO Reflector } \\
\text { Graphite Structures } \\
\text { Refractory Alloy Structures } \\
\text { Ceramics/Ceramic Composite Structures } \\
\text { Ni-Al, Ni-Mg Alloy Vessel; Au, CaF2 Vessel } \\
\text { High-Temp, Corrosion-Resistant Coating }\end{array}$ & $\begin{array}{l}\text { Synthesis of suitable refractory carbides } \\
\text { Fabrication of structural ceramic composites } \\
\text { Irradiation behavior of ceramics/composites } \\
\text { Protective coatings for metallic vessels } \\
\text { Environmental effects in UF4/UF6 } \\
\text { Irradiation, creep, embrittlement for HT alloys } \\
\text { Irradiation, reliability of ceramic composites }\end{array}$ \\
\hline $\begin{array}{l}\text { Plasma Fueled } \\
\text { Reactors }\end{array}$ & $>4000$ & Unspecified & $\begin{array}{l}\text { Materials issues similar to tokamak first wall } \\
\text { Thermal stability, thermal shock } \\
\text { Environmental effects, erosion } \\
\text { Many more issues! }\end{array}$ \\
\hline
\end{tabular}


Table 6. Costs for simple plate products (1996 prices) [2]

\begin{tabular}{|l|l|}
\hline Material & Cost per kg \\
\hline Fe-9Cr steels & $\leq \$ 5.50$ (plate form) \\
\hline SiC/SiC composites & $\begin{array}{l}>\$ 1000 \text { (CVI processing) } \\
\$ 200 \text { (CVR processing of CFCs) }\end{array}$ \\
\hline V-4Cr-4Ti & $\begin{array}{l}\$ 200 \text { (plate form--average between 1994-1996 US fusion program } \\
\text { large heats and Wah Chang 1993 “large volume" cost estimate) }\end{array}$ \\
\hline CuCrZr, CuNiBe & $\sim \$ 10$ \\
\hline Nb-1Zr & $\sim \$ 100$ \\
\hline Ta, Ta-10W & $\$ 300($ sheet form) \\
\hline $\mathrm{Mo}$ & $\sim \$ 80(3 \mathrm{~mm}$ sheet); $\sim 100$ for TZM \\
\hline $\mathrm{W}$ & $\sim \$ 200(2.3 \mathrm{~mm}$ sheet); higher cost for thin sheet \\
\hline
\end{tabular}




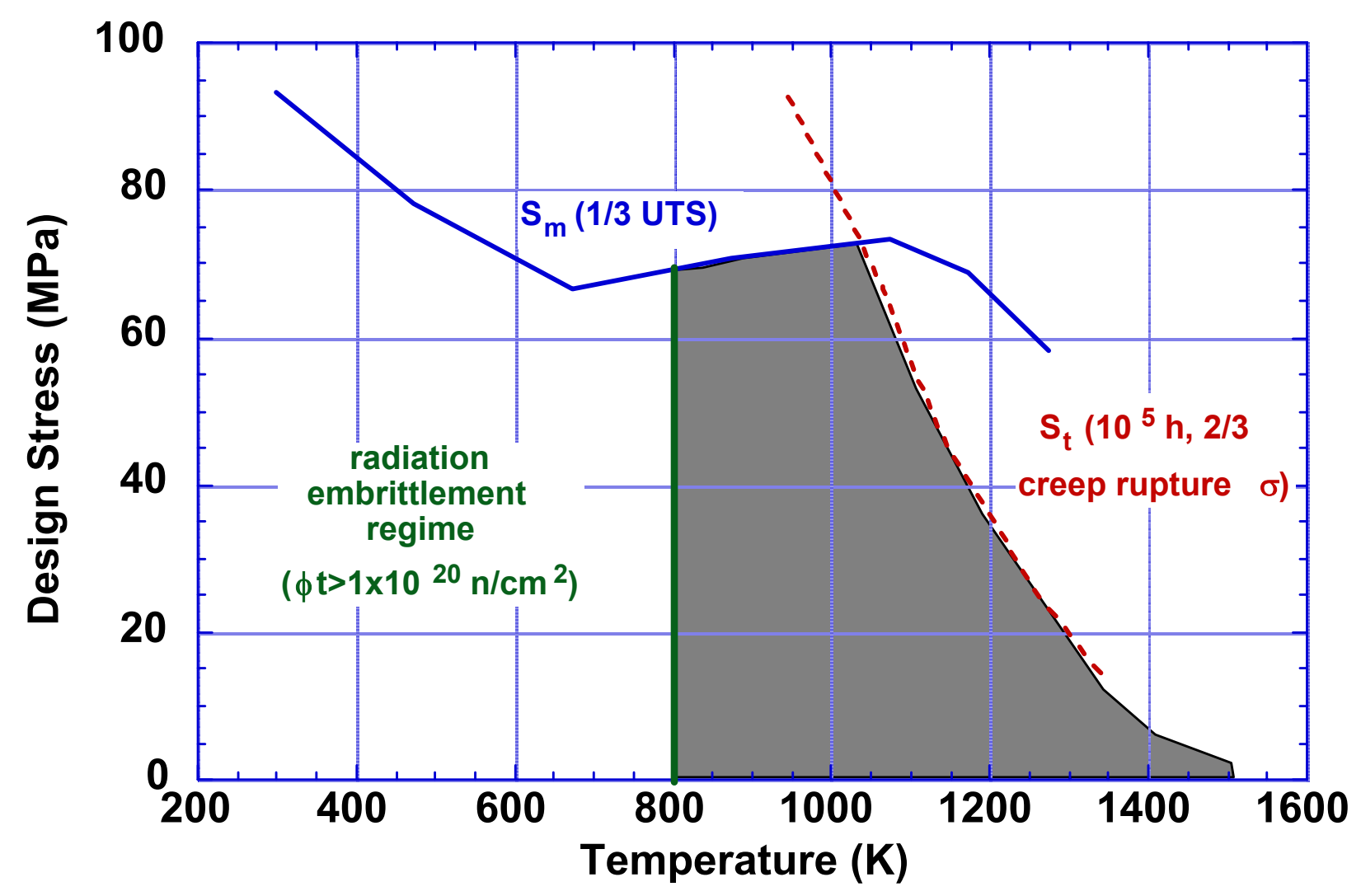

Figure 1. Stress-temperature design window for $\mathrm{Nb}-1 \mathrm{Zr}$ [1] 


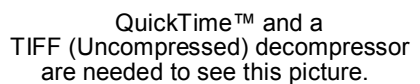

QuickTime ${ }^{\mathrm{TM}}$ and a

TIFF (Uncompressed) decompressor are needed to see this picture.

Figure 2. Operating temperature windows for various classes of reactor materials alloys. Top figure is for radiation doses up to $10 \mathrm{dpa}$. The second figure is for radiation doses up to $50 \mathrm{dpa}$. The upper and lower bands are temperature ranges where the materials performance may be adequate, but insufficient data currently exists to confirm performance. [1] 


\section{Damage Regimes as a Function of Homologous Temperature}

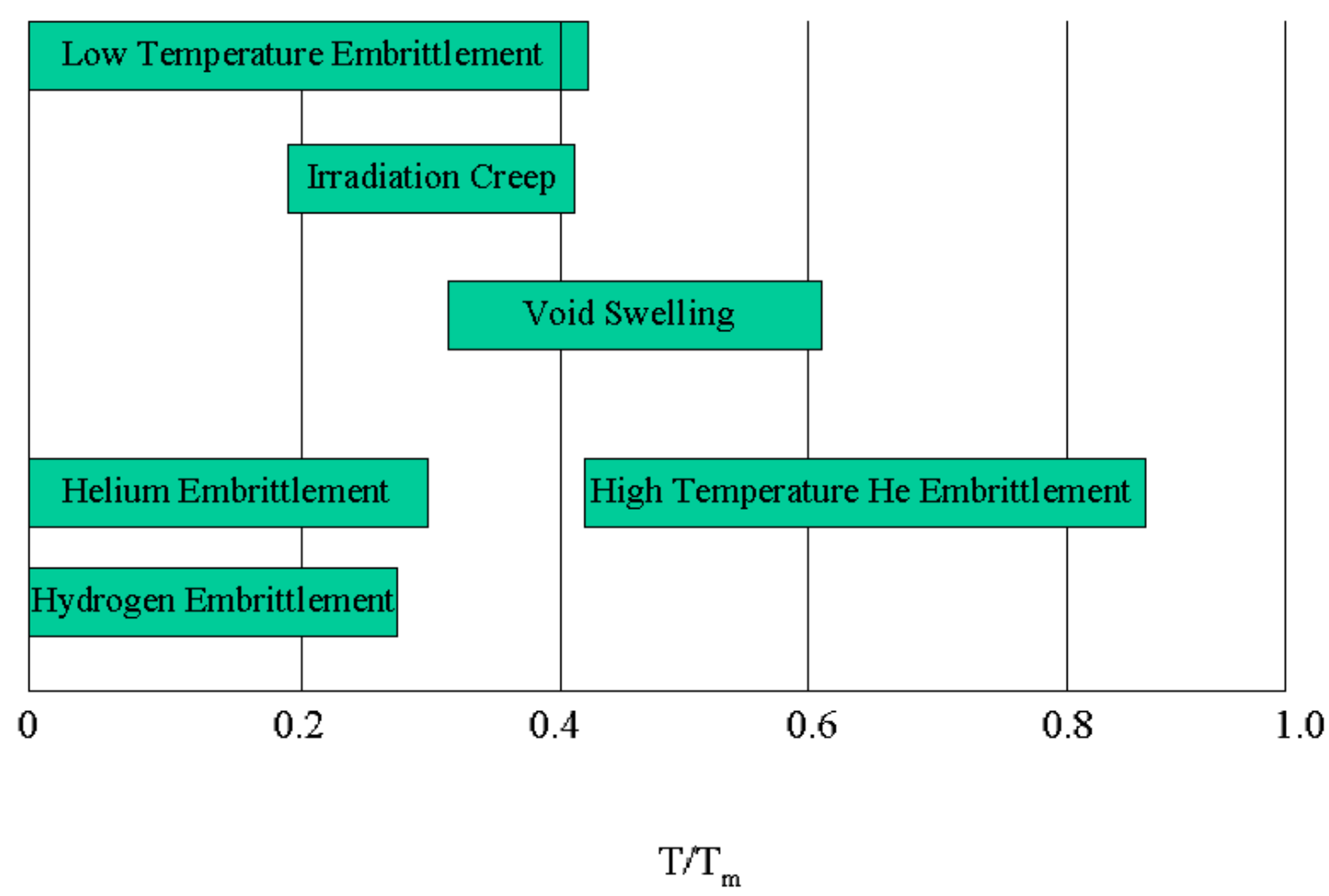

Figure 3. Temperature Ranges over which Radiation Damage Occurs 


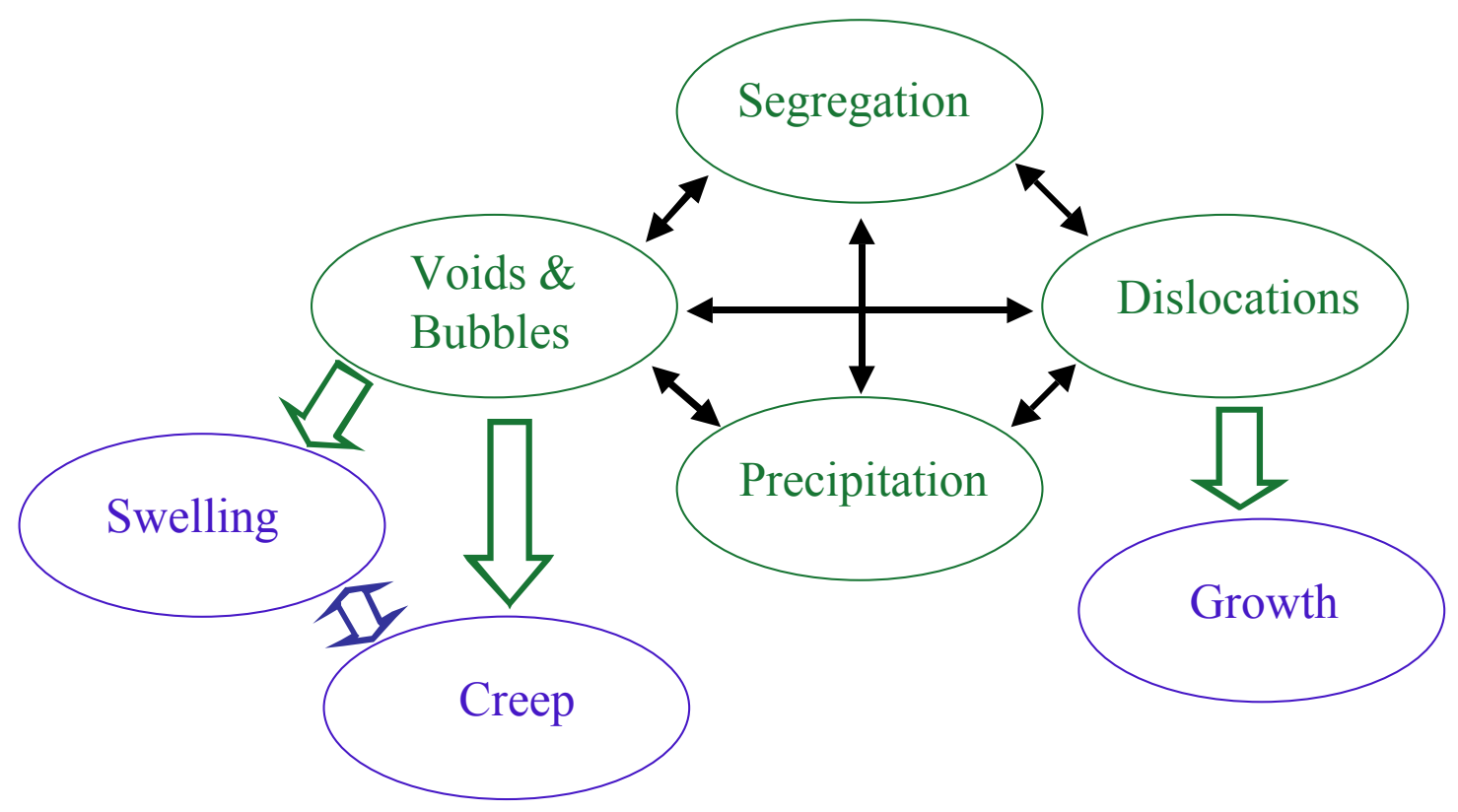

Figure 4. Relationship between microstructural features and dimensional stability 


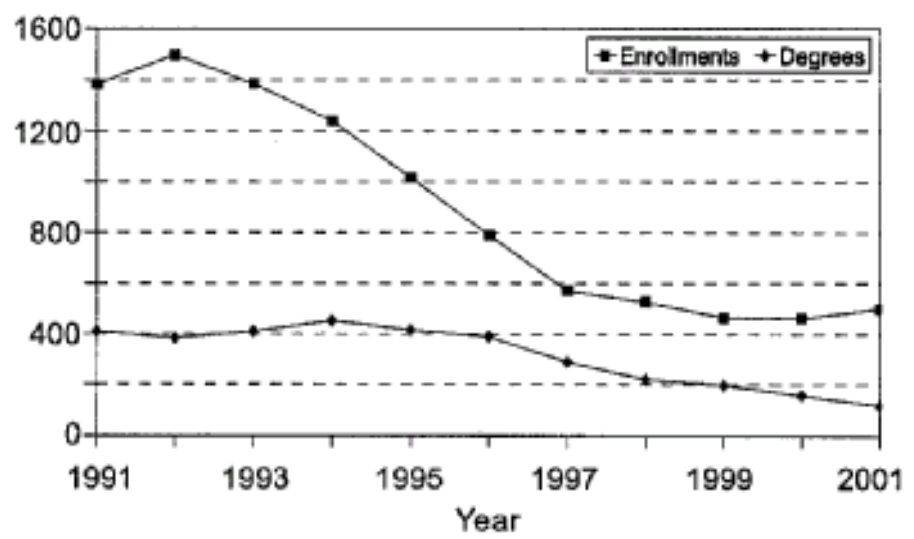

a)

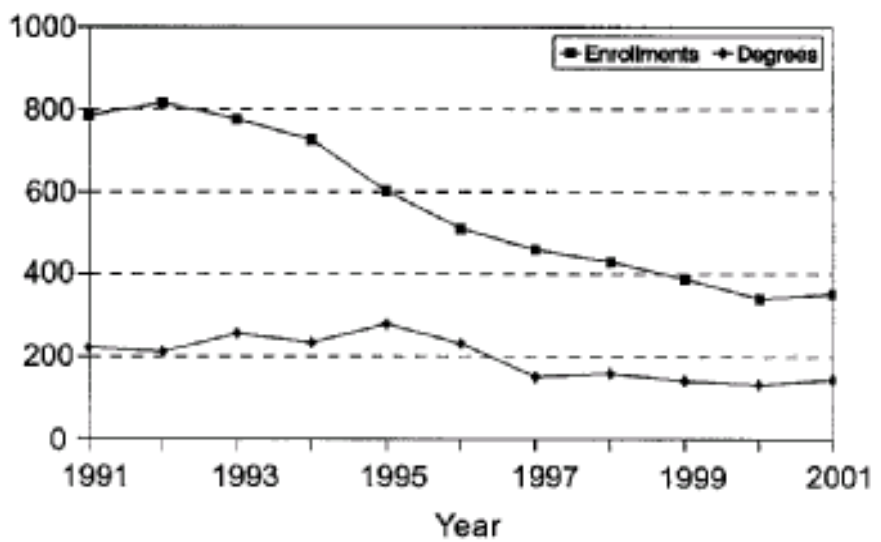

b)

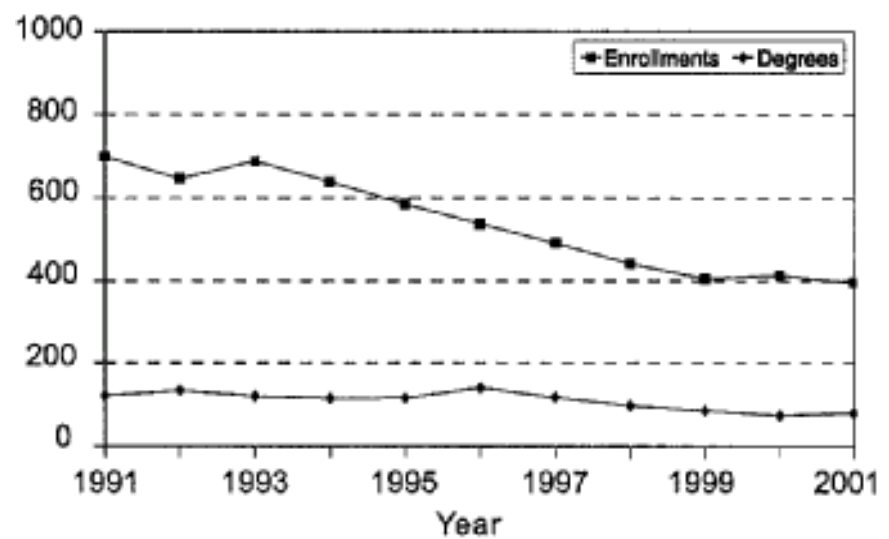

c)

Figure 5. Degree production and enrollment in a) BS, b) MS and c) PhD programs in nuclear engineering in the U.S. through 2001 [8] 


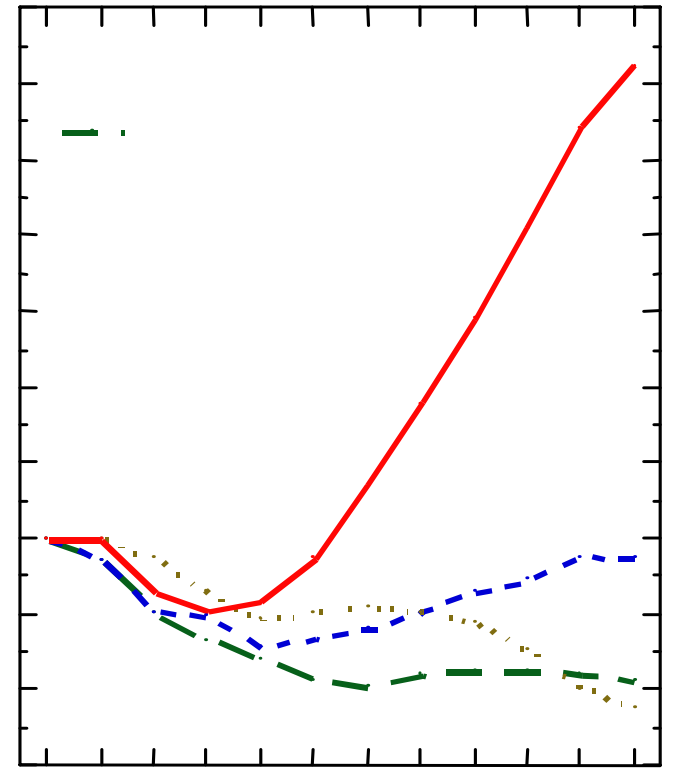

(a)

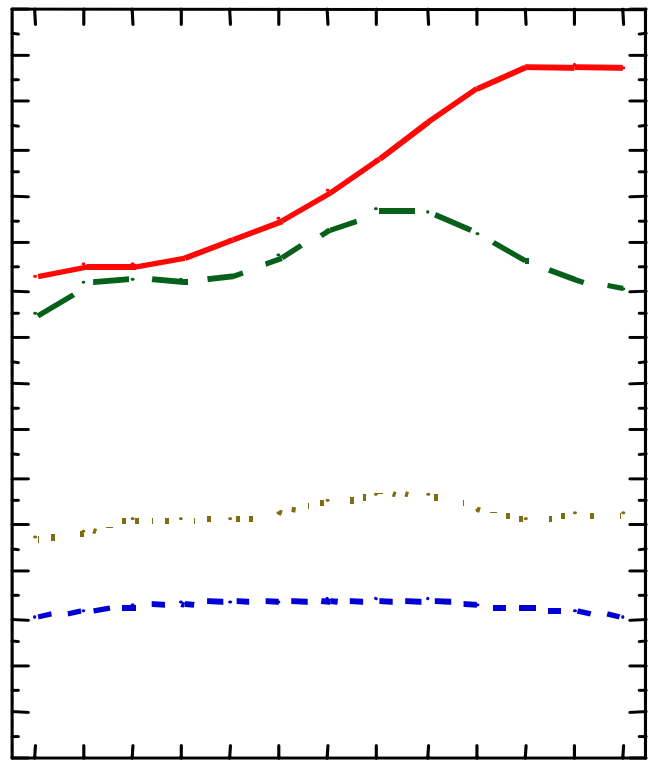

(b)

Figure 6. Increases in (a) undergraduate degrees and in (b) graduate enrollment in the biological/life sciences, physical sciences, mathematics and engineering. 


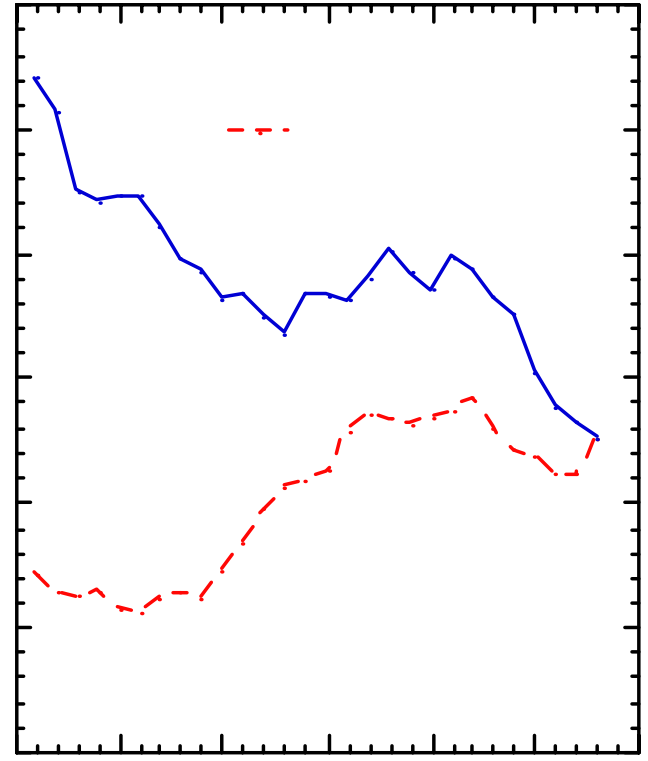

(a)

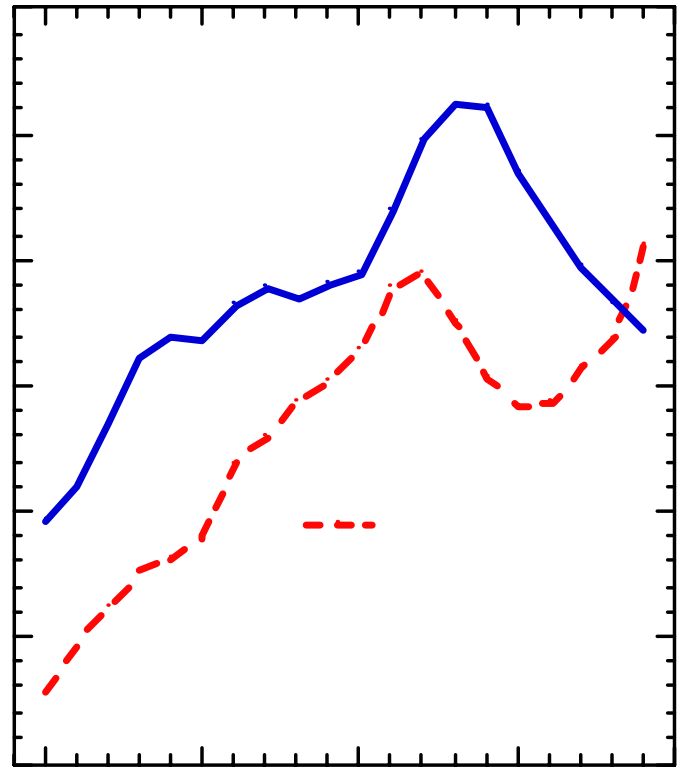

(b)

Figure 7. Change in numbers of foreign and U.S. graduate students in (a) physics and astronomy and (b) engineering between 1970 and 2000. 